\title{
NECESIDADES DE CONOCIMIENTO Y DESARROLLO ORGANIZACIONAL EN LA REGIÓN CENTRAL DE OCCIDENTE META-ANÁLISIS DE LAS INVESTIGACIONES REALIZADAS DESDE LOS SEMINARIOS DE REALIDAD NACIONAL
}

\section{KNOWLEDGE NEEDS AND ORGANIZATIONAL DEVELOPMENT IN THE WESTERN CENTRAL REGION META-ANALYSIS OF RESEARCH PROJECTS DEVELOPED FROM SEMINARIES OF NATIONAL REALITY}

\author{
Carlos Yurán Chavarría Carranzal \\ carlos.chavarria@ucr.ac.cr
}

\begin{abstract}
Resumen
Este artículo trata de las "resistencias al cambio" que afrontan organizaciones de la Región Central de Occidente (RCO), definidas aquí como necesidades de conocimiento (NC), que dificultan su desempeño interno y su eventual desarrollo y el de la región, de cara a las condiciones que impone el proceso de globalización neoliberal. Éstas fueron identificadas en 60 trabajos de investigación realizados desde los Seminarios de Realidad Nacional que se imparten en la Sede de Occidente de la Universidad de Costa Rica a lo largo de siete años. El análisis de cada trabajo permitió establecer que, de las 8 NC posibles, decantan como prioritarias conocer: cómo eliminar obstáculos para el trabajo eficiente, cómo incrementar la inclusión y satisfacción de las necesidades de las personas, cómo aprovechar habilidades y competencias para el trabajo en equipo y cómo fomentar una estrategia unificada.

Se discute que, a pesar de la importancia para el desarrollo organizacional, la NC orientada a conocer cómo mejorar la manera en que las personas se identifican con los objetivos de la organización sólo se identificó en un caso, y la NC que busca establecer cómo fomentar nuevas formas de liderazgo, no se encontró en ninguna de las investigaciones revisadas.
\end{abstract}

Palabras clave: Regionalización universitaria, desarrollo regional integral, investigación académica, necesidades de conocimiento organizacional.

\begin{abstract}
This article is on the "resistance to change" facing organizations in the West Central Region (WCR), defined here as Knowledge Needs (NC), which hinder their internal performance and eventual development and that of the region, given the conditions that are imposed by the neoliberal process of globalization. These were identified in 60 research papers from the National Reality Seminars which were held at the University of Costa Rica West headquarters for over seven years. The analysis of each project allowed establishing that, of the 8 possible $K N$, the priority is in knowing: how to eliminate obstacles for efficient work, how to better include and satisfy people's needs, how to take advantage of abilities and competences for group work, and how to bring forward a unified strategy.

It is argued that, in spite of the importance for organizational development, the KN oriented know how to improve the way people identify with the objectives from the organization identified in only one case, and seeking to establish how KN foster new forms of leadership, not found in any of the research projects analyzed.

Keywords: University regionalization, integral regional development, academic research, needs of organizational knowledge
\end{abstract}

1 Profesor del Departamento de Ciencias Sociales, Sede de Occidente, Universidad de Costa Rica. 


\section{Introducción}

\section{Seminarios de Realidad Nacional y desarrollo local}

Los Seminarios de Realidad Nacional (SRN) I y II que se imparten en la Universidad de Costa Rica fueron incorporados al currículo universitario por determinación del III Congreso Universitario en el año 1975 (UCR, 2009). Se definió como su objetivo primordial dotar a los y las estudiantes de los recursos conceptuales necesarios para desarrollar tanto una visión integral sobre las diferentes realidades locales, como una actitud crítica y propositiva frente a las problemáticas que en ellas se enfrenta.

A estos cursos les abriga una fuerte vocación interdisciplinaria pues se pretende que lleven al encuentro entre profesores y alumnos(as) provenientes de distintas disciplinas, todo con el fin de ampliar la perspectiva comprensiva y crítica de la realidad social. Pero, además, es de denotar que fueron concebidos como una suerte de articulador del quehacer institucional de la UCR para integrar, de alguna manera, las acciones docentes con las de acción social, de allí la propuesta de poner como objetivo la preparación previa del y la estudiante antes de matricular el Trabajo Comunal Universitario (TCU).

$\mathrm{Al}$ respecto se señala,

Las áreas temáticas de los Seminarios tienen relación con las áreas establecidas en los proyectos de trabajo comunal, ya que estos permiten vincular el quehacer universitario con la sociedad, y retribuir así su aporte, y ofrecen alternativas ante los problemas nacionales (UCR, 2009).

En el caso que nos ocupa, los seminarios que se ofrecen en la sede universitaria de la Región Central de Occidente (RCO) denominados Desarrollo Regional Integral (DRI), I y II (siglas SR0307 y SR0308, respectivamente), tienen como propósito que los y las estudiantes conozcan, se sensibilicen y adquieran compromisos alrededor de las distintas variables económicas, políticas, ambientales y psicosociales que caracterizan la vida de las personas, los grupos y las organizaciones que conforman en conjunto la vida social, societal y cultural de esta región.
Los objetivos del primer seminario son los siguientes:

1. Definir los elementos teóricos necesarios para sustentar las acciones tendientes a elevar cualitativa y cuantitativamente la calidad de vida de los habitantes y del país en general y de la región occidental de la Depresión Tectónica Central en particular.

2. Identificar las potencialidades económicas, sociales, políticas, culturales y espirituales que posee nuestra región y el país, para plantear alternativas viables en pro del desarrollo integral.

3. Capacitar a los estudiantes para que sugieran alternativas que permitan a los habitantes de la región de Occidente lograr ciertos niveles de desarrollo, tanto colectiva como individualmente.

4. Diseñar un proyecto de investigación que además de ser una investigación práctica incluya aspectos aplicados al desarrollo regional integral de la región de Occidente.

En el caso del segundo seminario, los objetivos planteados son:

1. Analizar la realidad socioeconómica de Costa Rica, tomando como punto de partida la situación mundial actual.

2. Reforzar las diversas etapas del quehacer investigativo científico.

3. Ejecutar un proyecto de investigación original de carácter práctico sobre alguna temática socioeconómica a nivel regional.

4. Caracterizar algunos de los problemas socioeconómicos nacionales y regionales con la idea de tener parámetros comparativos.

5. Preparar al estudiante para que asuma un mayor compromiso con las diferentes comunidades de la región de Occidente y pueda en un futuro próximo proyectarlo en su Trabajo Comunal Universitario.

Como puede notarse, en los objetivos 2 y 4 del primer seminario, y 2 y 3 del segundo, se plantea paralelamente la discusión y práctica sobre métodos y técnicas de investigación útiles para explorar, describir o evaluar aquellos 
aspectos que requieren especial atención en el marco de las condiciones que enfrentan las instituciones, organizaciones locales o grupos poblacionales en esta región y ofrecer con ello un aporte significativo para la toma de decisiones.

Para alcanzar con el mayor éxito posible esos propósitos, se sigue la siguiente ruta. En primera instancia, se induce a los y las estudiantes conformados en subgrupos a que tomen contacto con una institución, organización o grupo que sea de su especial interés e indaguen con estas personas o funcionarios(as) sobre los vacíos de conocimiento alrededor de las problemáticas o expectativas que buscarían subsanar a corto plazo.

El acopio de estas informaciones, datos en la medida de que se aporten registros, constituye el primer paso de toda investigación académica: la justificación.

Simultáneamente, se conforma el contexto de la investigación. Cuando así corresponda, se trata sobre todo de conocer los objetivos que guían a esa organización para que, en el marco de ellos, se concreten los aportes que se espera brindar y el grado de significancia que tiene para esa organización realizar la investigación.

Una vez establecida esta base, se abre a plenario cada caso para discutir y retroalimentar conjuntamente con observaciones alrededor de los aspectos temáticos y metodológicos que harán viable y útil el esfuerzo, en el corto plazo de un semestre.

En posteriores momentos, se consolida el marco de referencia que lleve a la construcción teórica del problema final de investigación y la estrategia metodológica que dé pie a la indagación empírica. Una vez realizado el acopio y ordenamiento de la información se abre de nuevo a plenario para evaluar en conjunto los análisis de resultados y arribar así a conclusiones sustentadas.

Documento en mano, al final del proceso, cada subgrupo se apersona de nuevo a la organización y realiza la correspondiente devolución de conclusiones y recomendaciones.

Claros de las debilidades que de todo tipo pueden padecer estos esfuerzos, dadas las limitaciones temporales, creemos que estas organizaciones se pueden beneficiar en varios sentidos, a saber:

- Tomar contacto teórico con una construcción posible sobre lo que requerían conocer.

- Hacerse de un modelo de investigación que pueden mejorar y llevarlo a mejores puertos.

- Conocer al menos algunas opiniones y representaciones que los y las participantes (muestra de estudio) evidencian sobre el problema planteado.

- Aprovechar el contacto generado con la UCR, Sede Regional de Occidente (SRO), ya que se puede constituir en lo sucesivo en un importante recurso con el que pueden contar, bajo ciertas condiciones, para mejorar su devenir.

Por su lado, la Universidad gana en gran medida al avanzar en sus expectativas de regionalización al constituirse claramente en un actor clave del desarrollo regional y fomentar sinergias entre las distintas organizaciones de la región. Además los y las alumnas participan de proceso formativo en el cual la relación teoría-práctica se vuelve significativa, o como diría Bleger (1985) el conocimiento generado es "vivo", pues se logra captar su utilidad y está bajo el dominio del o la investigadora que lo instrumenta.

Consideramos también que con este proceder se hacen aportes significativos en la consecución de los objetivos que guían a los Seminarios de Realidad Nacional, Desarrollo Regional Integral I y II.

\section{Noción del desarrollo en el marco de la globalización neoliberal}

En cuanto a los aspectos teóricos que son considerados en estos cursos, y con el fin de fomentar en el estudiantado la actitud crítica y propositiva sobre el devenir de las distintas realidades locales, que se definen como objetivos de los SRN (UCR, 2009), se estima que ello sólo es posible si las discusiones se sustentan sobre:

- El debate crítico del concepto de Desarrollo.

- La descripción de fuerzas que actúan externamente sobre cada país y, dentro de sus límites, sobre las localidades. 
- El debate sobre la naturaleza humana, fuente y meta del desarrollo (Carvajal, 2009).

Se muestra a continuación la posición que en esos aspectos guía a quien suscribe este trabajo y que pone a debate en sus cursos con los y las estudiantes.

En términos generales el concepto de desarrollo ha sido definido tomando como base tres criterios principales que actúan como valores, a saber: la idea del progreso material, el acceso a las nuevas tecnologías y alcanzar los niveles de vida de las personas que, no por casualidad, se definen como desarrollados (Carvajal, 2009).

Tomada así, esta noción de desarrollo tendría varios problemas. El primero radica en la imposición de una suerte de estilo de vida ideal al que los demás, por tanto no desarrollados, deben aspirar y seguir como deseables. En razón de lo anterior, el desarrollo devendría en un mero juicio de valor que otorgaría preeminencia a aquellas personas o grupos que lo evidencien como forma de vida. Y el tercer problema es que el desarrollo sería un proceso vertical, de arriba hacia abajo. De todo ello se deriva como corolario que quienes se encuentran en los escaños más bajos sólo podrán alcanzar el desarrollo si los grupos o países que se ubican en las posiciones más altas facilitaran de alguna manera el acceso o, como se dice, derramaran las técnicas, mercancías o códigos culturales que detentan (Carvajal, 2009).

Esta noción es la que, al parecer, orienta al avasallante proceso de globalización que vivimos en la actualidad y que no en vano se define según Estefanía (2004) como: “... proceso mediante el cual las políticas nacionales tienen cada vez menor importancia y las políticas internacionales, aquellas que se deciden lejos de los ciudadanos, cada vez más".

Producto de esta lógica impuesta, vertical y prejuiciada, es que diversos pensadores (Fisas, 1998; Chomsky, 2004; Crouch, 2004; Estefanía, 2004; Santos, 2004; Chavarría y Robert, 2011) afirman que los principales efectos de esta tendencia siguen siendo, sólo por decir algunas:

- Aumento del flujo de capital en el mundo.
- Invertir la ecuación: producción vrs. especulación. Un altísimo porcentaje del capital se dedica en la actualidad a la especulación.

- Aumento considerable de la pobreza y el desempleo.

- Desplazamiento de grupos poblacionales. Sin embargo, la libre circulación que se le garantiza a las mercancías y los capitales se le niega a las personas.

- Los países ricos exportan bienes y servicios. Los pobres se vuelven proveedores de mano de obra barata y de materias primas.

- Tendencia a la homogenización cultural con sus consecuentes polarizaciones.

- Aumento de patologías sociales, mentales y psicosomáticas.

- Deterioro ecológico.

Es difícil que aflore el optimismo cuando vemos que estos dramas se acrecientan en todos los niveles de la vida; desde los conflagraciones que se libran en diferentes lugares en el mundo, las hambrunas y desastres naturales que deben enfrentar los países, las diferentes patologías sociales que viven las comunidades y las familias, hasta los dilemas existenciales que aquejan a las personas concretas.

¿Desde dónde es medianamente coherente mostrar que otra visión del desarrollo es posible? Firmemente respondemos y ponemos a debate el rescate de una perspectiva Humanista del desarrollo que lleve a confrontar los supuestos que sustentamos (antropología personal) sobre la naturaleza humana que ha sido sistemáticamente dejada de lado (Geibler y Hege, 1997).

Un debate más prolijo de esta perspectiva se puede consultar en otros lugares (Fromm,1977; Chavarría, 2009; Chavarría, 2012). Sin embargo, valga como resumen la siguiente cita de Chavarría (2012): "Tanto a nivel filogenético (como especie) como ontogenético (como sujetos individuales) damos evidencias de que, si contamos con las condiciones adecuadas, sobre todo de apoyo social, podemos alcanzar mayores estándares de desarrollo en todos los ámbitos de nuestra existencia".

$\mathrm{Si}$ las personas logran satisfacer sus necesidades, sobre todo de índole existencial, aflorarán en ella actitudes de vinculación y respeto 
por los demás y por la naturaleza (Fromm, 1977; Pereira, 2002).

\section{Enfoque alternativo del desarrollo: el desarrollo local}

Congruente con lo anterior, nos hacemos eco de las voces que se han levantado para proponer un modelo de desarrollo distinto al que definen y alientan las grandes entidades financieras internacionales como el Banco Mundial y el Fondo Monetario Internacional (Santos, 2004). En vez de fomentar un desarrollo "desde arriba" como se ha venido dando, debiera fomentarse un modelo de desarrollo distinto, que se plantee su accionar "desde abajo" (Carvajal, 2009) y que tome como fundamento la vocación productiva y la dinámica socio-cultural de las comunidades.

Cuando la línea del desarrollo se impone "desde arriba" se genera en las comunidades el efecto de vaciarlas del lazo cultural que había regulado la vida social y material de las personas. Pero si se hacen esfuerzos por fomentar el desarrollo "desde abajo" se tomarán en cuenta las necesidades particulares de cada población y se gestionarán las acciones que lleven a fortalecer el tejido social, institucional y productivo para alcanzar mejores indicadores en la vida material, laboral, educativa, de la salud y personal de quienes conforman esa comunidad, de una manera cada vez más inclusiva (Carvajal, 2009).

Desde esta perspectiva, el espacio local pasa a tomar una importante preeminencia. Cuando se habla de "lo local", según Valverde (2000) se está haciendo referencia a tres dimensiones:

- Dimensión espacial. Porción de territorio dentro de otro mayor que es la nación.

- Dimensión social. Actividad consuetudinaria, política y económica que realizan las personas dentro de los límites de ese territorio.

- Dimensión cultural. Códigos (sistema de valores y costumbres) compartidos por esa población.

Visto el desarrollo como desarrollo local, se entendería según Gabriela Orduna (en: Carvajal, 2009) como: “... un proceso global, integrado y sostenible de cambio social, protagonizado por la comunidad, organizada en un territorio bien definido, que participa activamente en el aprovechamiento de los recursos locales: humanos, materiales, naturales, financieros y sociales, para la mejora de sus condiciones de vida".

Evidencia importante en ese sentido se encuentra en la investigación que reporta Chantarasombat (2011). Tomando como base una muestra por conglomerados de dos comunidades tailandesas evidencia que el apoyo al mejoramiento de la salud integral de las personas en el espacio local conlleva importantes réditos para la convivencia pacífica entre sus pobladores y el sentimiento de bienestar en ellos-as.

Taghvaei y Shaykh-Baygloo (2011) indagaron en la totalidad de regiones (subprovincias les llaman) de Irán los tres componentes (educación, esperanza de vida al nacer y capacidad de consumo) que regularmente evalúa el Índice de Desarrollo Humano (IDH) a nivel internacional. Junto a esto crearon un instrumento donde definen lo que denominan "reglas difusas" para establecer otro índice que denominaron Nivel de Desarrollo (ND) y que consta de siete escaños en forma de escala ascendente con el fin de determinar de forma más precisa el desarrollo alcanzado en cada región.

Concluyen que en este país se evidencian claras diferencias en cuanto al IDH y el ND entre las distintas regiones estudiadas. Afirman que estas diferencias son las que en gran medida están detrás de los disturbios sociales, inestabilidad política y la desintegración que aquejan a esa nación.

Aunque no necesariamente nos adherimos a estas conclusiones, es importante denotar la importancia que cobra la desagregación regional (local a efectos nuestros) para avanzar de forma significativa en la promoción del desarrollo en los diferentes espacios locales, dando cara a la satisfacción de sus propias necesidades.

Muñoz (2008) informa sobre su participación en un proceso continuo de capacitación para debatir alrededor de prácticas exitosas de desarrollo rural y local denominado "La Ruta del Aprendizaje". Destaca en este proceso la participación activa de las actrices y los actores locales con el fin de que se constituyan en futuros capacitadores 
Dentro de los principales logros que según la investigadora se han alcanzado, destacan:

Conocer las barreras que impedía a los productores locales acceder y encontrar nuevos y mejores mercados, visualizar distintas formas de inserción en ellos y promocionar la identidad territorial de las regiones donde se asientan las organizaciones.

Es notoria entonces la necesidad de dar la palabra a los actores sociales y societales que constituyen una realidad local. ¿Cómo hacerlo desde el quehacer universitario en la RO?

Antes una precisión. En adelante este trabajo se aboca a sustentar una propuesta teórica que permita instrumentar a quien la acoja para realizar análisis que se dirijan más a los a los procesos humanos que se suscitan en toda organización social, que a los aspectos formales y descriptivos que han privado cuando se tratan de atender las dificultades en el desempeño de una organización.

Denominamos a este constructo necesidades de conocimiento (NC), y con ello ponemos a debate su utilidad o no para favorecer el mejoramiento de las organizaciones locales y así al desarrollo regional integral desde abajo.

\section{Satisfacción de las Necesidades de Conocimiento (NC) para el desarrollo de las organizaciones locales}

Algunas propuestas para fomentar el desarrollo local (Carvajal, 2009) describen las áreas de trabajo que deben atenderse. Entre otras señalan los aspectos económicos (trabajo, producción, etc.), sociales (igualdad, convivencia, justicia social, salud, educación, etc.), culturales (pertenencia, identidad, integración, etc.) y políticos (transparencia, participación, toma de decisiones, etc.).

Valverde (2000) propone el abordaje de aspectos similares, pero distingue lo que debieran atender particularmente las Organizaciones no Gubernamentales, con financiamiento propio o internacional, los municipios y hasta lo que correspondería a la propia población civil organizada.

Es en ese sentido que se realiza la gran mayoría de las investigaciones. Sólo por poner dos ejemplos, Quesada (2000) aborda las dificultades que enfrentan las mujeres en su afán de participación social, y el ya citado trabajo reportado por Muñoz (2008) sobre la participación activa de los productores al desarrollo local.

Este tipo de trabajos se concentra en atender aspectos específicos dentro de las áreas temáticas del desarrollo local que recién señalamos, pero no es a ello a lo que en este trabajo nos referimos como Necesidades de Conocimiento (NC). De hecho, las NC en las organizaciones sociales están detrás de los temas-problemas que se indagan o atienden en ellas.

Para esclarecer el concepto de NC es necesario comprender primero que toda organización, sea esta social, laboral, empresarial, etc., se encuentra en un cambio constante (Robbins, 1987; Davis y Newstrom, 2000), ya que debe enfrentar presiones que emanan de las mismas $\mathrm{y}$ recurrentes transformaciones que se generan en los contextos donde insertan su actividad y también de la dinámica interna que se complejiza invariablemente como producto de su propio desenvolvimiento (Arras y Jáquez, 2008).

En el caso del desarrollo local, ese cambio debe llevar a una mayor integración societal y a una mayor inclusión y participación social, tal y como supra señalara Orduna (en: Carvajal, 2009). Pero muchas veces no es así.

A pesar de que esta "realidad en movimiento" debiera ser tomada por las organizaciones como una oportunidad para su propio progreso, ya que toda organización es perfectible, muchas veces las cosas no son tomadas de esta manera y más bien se oponen a ello, lo que genera el fenómeno conocido como "resistencia al cambio" (León, 2009; Predişcan y Săcui, 2011). Característica que radica en la propia naturaleza humana (Freud, 1930/1981), aunque mediada por diferencias culturales (León, 2009; Tamayo y De Oliveira, 2001) y a la que propende toda organización cuando se estabilizan en los valores de quienes integran una organización (Robbins, 1987; Tamayo y De Oliveira, 2001).

En el mismo sentido, nos parece que Schwars y Ros (1995) hacen referencia a esta condición cuando señalan, en relación con la estimación de los valores en diferentes culturas, que toda organización debe enfrentar tres retos 
fundamentarles: 1) la confrontación de los valores e intereses de los individuos y los grupos, 2) el establecimiento de una estructura que garantice el logro de las metas y los objetivos organizacionales y 3) la relación de la organización con el medio ambiente físico y social.

Cable y Furst (2008) también apuntan a la necesidad de ser conscientes de la distancia que se da entre las metas, intereses y necesidades personales frente a los de la organización a la que se pertenece, con el fin de trabajar a favor de que se logre la mayor cooperación entre las personas para enfrentar el cambio que debe experimentar toda organización cuando deba adecuar su actuar a condiciones que son distintas a las que se habían acostumbrado.

Resistirse a atender estas cuestiones lleva a que las organizaciones deban enfrentar más y diversas dificultades de funcionamiento, a una menor calidad de los servicios que ofrecen y a una menor satisfacción en los y las usuarios-as de los servicios o productos que en ellas se dan.

Cuando se enfrentan mayores dificultades para el trabajo en equipo, cuando se hace más difícil llegar a acuerdos, cuando las metas no terminan por alcanzarse, o los productos bajan de calidad, cuando aumentan las quejas de los y las usuarias, cuando aumenta el clima de malestar en el lugar de trabajo, etc., es cuando emergen las NC.

En consecuencia, las NC son los requerimientos, más o menos conscientes, de informaciones que demandan las organizaciones para entender las resistencias al cambio que se suscitan entre quienes conforman cada organización en distintos niveles y momentos, para luego afrontarlas y favorecer así su desempeño.

A diferencia de los temas-problema que se indagan o atienden en las organizaciones, las NC están referidas al propio funcionamiento de la organización y más específicamente a las relaciones humanas que son "cemento y acicate" del desempeño y de la cultura que las diferencia de otras organizaciones (Robbins, 1987; Davis y Newstrom, 2000).

Valga aclarar que las relaciones humanas no se refieren únicamente a las que se dan dentro de los límites de un organigrama o de manera informal, sino que incluyen también las poblaciones meta a las que cada organización espera alcanzar, ya que en ellas, en su conocimiento, efectos, valoraciones, etc. se extiende el quehacer organizativo.

Predişcan y Săcui (2011), muestran en su artículo una serie de acciones que llevarían a afrontar la resistencia al cambio en las organizaciones. Estas acciones se corresponden perfectamente con lo que hemos denominado NC ya que están dirigidas a fomentar los valores y actitudes necesarias para que las personas faciliten el logro de las metas y objetivos de la organización.

Presentadas como Necesidades de Conocimiento, esas acciones se exponen a continuación en forma de consultas y se amplían en aquellos aspectos que den mejor sustento a los análisis posteriores. Ellas son:

1. ¿Cuáles son las motivaciones de las personas para lograr los objetivos de la organización? ¿Están identificadas con la visión y los objetivos que persigue? Se refiere a la confrontación de los valores e intereses individuales frente a los organizacionales.

2. ¿Cómo formar equipo y aprovechar las habilidades y las competencias de los y las integrantes a diferentes niveles? Se refiere a las competencias personales para el trabajo en equipo.

3. ¿Cómo unificar la estrategia en los y las participantes para impulsar el ofrecimiento eficiente de los servicios? Esta NC implica el sustento de modelos y métodos de trabajo que, por mostrar su eficiencia, debiera ser compartido por los y las participantes de la organización.

4. ¿Cómo lograr una mayor inclusividad y dar respuesta a las necesidades de las personas? Esta NC se refiere a la forma de superar las barreras discriminatorias que inhibe a algunas personas o grupos de una mayor participación e integración organizacional.

5. ¿De qué manera se pueden eliminar obstáculos y apoyar las iniciativas, avances y logros? La NC que se muestra en esta consulta está orientada a establecer la forma en que deben apoyarse las iniciativas que llevaron a la implementación de programas y proyectos, mediante el conocimiento de las dificultades 
que enfrentan en su implementación y que tergiversan la posibilidad de alcanzar mejores resultados.

6. ¿Cómo finalizar etapas y abrirse a otras nuevas? Los cambios que se generan en cuanto a nuevas tecnologías o formas de trabajo hace que aflore esta NC. Para implementar el uso de esa nueva tecnología o práctica de trabajo requiere de informaciones útiles que ayuden a superar el nivel de la creencia o el rumor. De esta forma se facilita persuadir para la toma de decisiones, en un sentido u otro.

7. ¿De qué manera promover y fomentar la determinación y la perseverancia alrededor de las acciones en curso? El ímpetu y el compromiso inicial con el que se asumen las actividades que requiere una iniciativa tienden a decrecer en las personas a lo largo del tiempo. Dado que esta realidad está moderada por variables propias de las personas, se requiere conocerlas para reanimar a partir de su conocimiento, por así decirlo, lo que está en ejecución.

8. ¿Cómo fomentar nuevos liderazgos y el desarrollo de la cultura organizacional? Es una realidad que los valores e intereses de los líderes tienden a imponerse como propios de las organizaciones (Robbins, 1987; Tamayo y De Oliveira, 2001). Esto puede llevar a que se marque un camino distinto al que se espera que siga la organización. El desarrollo organizacional requiere regularmente ajustes en estos niveles (Cable y Furst, 2008).

Como puede notarse, las NC no se refieren a temáticas concretas, sino al conocimiento que deben generar para mejorar el funcionamiento interno de la organización. Es así que el trabajo realizado por Quesada (2000) dirigido a conocer las dificultades que enfrentan las mujeres en su afán de participación social expresaría, según lo expuesto, una NC 4 ¿cómo lograr una mayor inclusividad y satisfacer las necesidades de personas concretas? El trabajo de Muñoz (2008) sobre la participación activa de los productores se correspondería con la NC 2, dirigida a informarse sobre nuevas formas de relación entre las personas.

Las respuestas a esas preguntas debieran constituirse en insumos valiosos para que las organizaciones tomen las decisiones pertinentes para solventar las deficiencias, dado que son en el fondo formas de resistirse al cambio.

\section{Método}

\section{Selección de los estudios}

Dado que quien suscribe este informe ha fungido como profesor de los cursos Seminario de Realidad Nacional: Desarrollo Regional Integral I y II, acopió a lo largo de los últimos 7 años un total de 60 informes de investigación, supervisadas por él mismo según la forma que se expuso supra, y que fueron coordinadas con organizaciones pertenecientes a diversos sectores de la vida social y productiva de la RCO.

Ya que todos esos informes fueron considerados en los análisis, la tabla 1 muestra el

Tabla 1

Total de investigaciones según sector donde fueron realizadas

\begin{tabular}{cccccccc}
\hline Sector & Educación & $\begin{array}{c}\text { Atención } \\
\text { Social }\end{array}$ & $\begin{array}{c}\text { Gobierno } \\
\text { Local }\end{array}$ & Salud & Productivo & Ambiente & Total \\
\hline Total & 20 & 13 & 11 & 8 & 7 & 1 & 60 \\
\hline
\end{tabular}

Elaboración del investigador a partir de los trabajos presentados por los y las estudiantes de los Seminarios de Realidad Nacional. 
universo de ellos según el sector con el que se coordinó su realización.

Es importante aclarar que la elección de la organización con la que se coordinó la investigación respondió más a los intereses de los y las estudiantes. Han sido pocas las organizaciones que, como el Programa de Promoción de la Salud del Ministerio de Salud o alguna oficina o programa de la UCR-SO, por iniciativa propia hayan solicitado la realización de alguna investigación específica.

Otro aspecto que vale la pena aclarar es que, a pesar de que la investigación se haya realizado para una organización perteneciente a un sector en particular, el tema-problema que se indagó puede ser sobre algo distinto. Por ejemplo, investigaciones realizadas para organizaciones del sector educación solicitaron la indagación de problemas relacionados con temas de salud. $O$ en el caso de centros de salud que solicitaron que se investigaran problemas relacionados con temas de satisfacción en los y las usuarias de los servicios.

Esto no implica ningún inconveniente, ya que el objeto de estudio que se busca establecer es la NC que da pie a la investigación en cada organización.

\section{Procedimiento}

A cada estudio se le dio el mismo tratamiento. Dado que el tema-problema de investigación debe al final responder a las inquietudes expuestas en la justificación de cada trabajo, se toma ésta como el punto de partida del análisis para establecer las NC. En cada caso se establecieron primero los fundamentos justificatorios que el grupo de estudiantes a cargo reportó como datos a partir de las entrevistas o documentos que les fueron entregados por la contraparte en cada organización.
Valga recordar que la justificación de toda investigación se basa en contestar a la pregunta: ¿Por qué es necesaria la realización de la investigación? Datos como: cantidad de quejas de usuarios, número de incapacidades médicas, aumento de costos, pobreza en el logro de resultados, y un largo etcétera, permitió establecer la demanda inicial de indagación.

Posteriormente, se verificó que la base justificatoria fuera congruente con el tema - problema que al final se investigó, ya que éste debía ser avalado por la contraparte en la organización. Se estableció la correspondencia entre ambos para extraer de ello la NC subyacente. Por último, se numeró la NC (de 1 a 8) según la descripción supra escrita.

Una vez logrado todo esto, se procedió a realizar el meta-análisis sobre las $\mathrm{NC}$ que, en razón de su frecuencia, se decantan como prioritarias en las organizaciones de la RCO.

\section{Resultados}

En un principio, se valoró la posibilidad de conformar un tipo de tabla expositiva tomando como criterio el tema - problema de la investigación realizada, ya sea este de índole social, económico, etc. Sin embargo, tal propósito se desestimó al tomar en consideración la importancia de construir cada tabla a partir de la organización beneficiaria del trabajo ya que posibilita, además de mostrar el temaproblema, establecer las NC de cada una y las que son más recurrentes según al sector al que pertenecen.

A continuación, se muestran las organizaciones con las que coordinó, el tema-problema (resumido en algunos casos para efectos expositivos) y la NC establecida para cada caso.

La tabla 2 muestra que han sido 20 organizaciones del sector educación con las que se ha coordinado la realización de los trabajos de 
Tabla 2

Organización beneficiada, tema-problema abordado y Necesidad de Conocimiento establecida en el sector educación

\begin{tabular}{|c|c|c|}
\hline Organización & Tema - Problema & NC \\
\hline UCR-SO & $\begin{array}{l}\text { Promoción de la Salud en la Sede de Occidente. Evaluación del programa. } \\
\text { (Barrios, Campos, Castillo, Lobo y Sánchez, 2008) }\end{array}$ & 5 \\
\hline UCR-SO & $\begin{array}{l}\text { Evaluación de los docentes formados sobre la eficacia del TCU: "Fortaleciendo } \\
\text { la educación cooperativa" de la Sede de Occidente. (Bolaños, Chavarría, } \\
\text { Cubero e Hidalgo, 2009) }\end{array}$ & 5 \\
\hline UCR-SO & $\begin{array}{l}\text { Enseñanza interactiva de las matemáticas. } \\
\text { Condiciones físicas, ambientales y espaciales requeridas en el aula. (Angulo, } \\
\text { Cruz, Fernández y Solano, 2009) }\end{array}$ & 4 \\
\hline UCR-SO & $\begin{array}{l}\text { Valoración de condiciones físicas y sociales y el sentido de autoeficacia en } \\
\text { estudiantes de residencias UCR-SO. (Bolaños, Bolaños, González, Mora, y } \\
\text { Ledezma, 2009) }\end{array}$ & 4 \\
\hline UCR-SO & $\begin{array}{l}\text { Proyecto Casa Infantil de la UCR-SO. Investigación evaluativa de sus objeti- } \\
\text { vos. (Álvarez, Bolaños, Castro, Cortés, Espinoza, Ramírez y Vega, 2010) }\end{array}$ & 5 \\
\hline UCR-SO & $\begin{array}{l}\text { Formación humanística. Valoración de los y las estudiantes de la UCR, Sede } \\
\text { de Occidente. (Ramírez y Rodríguez, 2010) }\end{array}$ & 1 \\
\hline UCR-SO & $\begin{array}{l}\text { Fortalezas universitarias para el apoyo a la Casita Infantil de la UCR, Sede de } \\
\text { Occidente. (Benavides, Chávez, Fonseca, Ramírez y Rodríguez, 2011) }\end{array}$ & 2 \\
\hline UCR-SO & $\begin{array}{l}\text { Estrategias de afrontamiento del estrés que emplean los profesores de la UCR- } \\
\text { SO. (Álvarez, Artavia, Carvajal, Jiménez, Morales, y Villalobos, 2011) }\end{array}$ & 4 \\
\hline UCR-SO & $\begin{array}{l}\text { Actitudes sobre la homosexualidad en estudiantes de la UCR, Sede de } \\
\text { Occidente. (Rodríguez, Sánchez y Soto, 2011) }\end{array}$ & 4 \\
\hline UCR-SO & $\begin{array}{l}\text { Actitudes del-la docente hacia las estudiantes madre. UCR-SO. (Araya, Arias, } \\
\text { Chavarría, Jiménez y Urbina, 2012) }\end{array}$ & 4 \\
\hline Instituto Julio Acosta & $\begin{array}{l}\text { Incentivos económicos de FONABE y motivación para continuar en el sistema } \\
\text { educativo. (Arias, Horna, Piedra, y Rojas, 2007) }\end{array}$ & 4 \\
\hline Instituto Julio Acosta & $\begin{array}{l}\text { Uso de videojuegos y sentido de autoeficacia en estudiantes de colegio. (Arce, } \\
\text { Jiménez, y Rodríguez, 2010) }\end{array}$ & 5 \\
\hline Instituto Julio Acosta & $\begin{array}{l}\text { Motivación intrínseca - extrínseca y condiciones físico ambientales en un } \\
\text { colegio público. (Hidalgo, Rodríguez, Torres y Vargas, 2010) }\end{array}$ & 5 \\
\hline Escuela Federico Salas Carvajal & $\begin{array}{l}\text { Satisfacción de los estudiantes de I y II ciclo con respecto al servicio de come- } \\
\text { dor escolar. (Charpentier, Fernández, Montoya, Jiménez y Quesada, 2007) }\end{array}$ & 4 \\
\hline $\begin{array}{l}\text { Escuelas Jorge Washington y José } \\
\text { Joaquín Salas Pérez }\end{array}$ & $\begin{array}{l}\text { Accesibilidad de personas discapacitadas a las instalaciones físicas de las } \\
\text { escuelas públicas y privadas del distrito central de San Ramón. (Corrales, } \\
\text { Jiménez, Muñoz, y Soto, 2007) }\end{array}$ & 4 \\
\hline $\begin{array}{l}\text { INA } \\
\text { Comunidad Tacares }\end{array}$ & $\begin{array}{l}\text { Adecuación entre la oferta de carreras y la demanda laboral. (Campos y } \\
\text { Rodríguez, 2008) }\end{array}$ & 4 \\
\hline $\begin{array}{l}\text { Colegios Copán y La Libertad. } \\
\text { Piedades Norte }\end{array}$ & $\begin{array}{l}\text { Conocimiento sobre sexualidad que tienen los padres y madres de hijos-as } \\
\text { entre } 10 \text { y } 16 \text { años. (Carvajal, Castillo y Cortés, 2011) }\end{array}$ & 5 \\
\hline $\begin{array}{l}\text { Colegio Nuestra Señora de los } \\
\text { Ángeles }\end{array}$ & $\begin{array}{l}\text { Prácticas y motivaciones de consumo de sustancias adictivas en colegiales de } \\
\text { la RO. (Alfaro, Campos, Gómez y Ledezma, 2011) }\end{array}$ & 5 \\
\hline Colegio Patriarca & $\begin{array}{l}\text { Valoración de los y las docentes sobre la eficacia del programa D.A.R.E en la } \\
\text { prevención de consumo de drogas en una población adolescente. (Barquero, } \\
\text { Bonilla, Corea, Ledezma, y Madrigal,, 2012) }\end{array}$ & 5 \\
\hline Biblioteca Pública de Palmares & $\begin{array}{l}\text { Conocimiento de los servicios por los y las usuarias. Biblioteca de Palmares. } \\
\text { (Barquero, Fernández y Salas, 2010) }\end{array}$ & 5 \\
\hline
\end{tabular}

Elaboración del investigador a partir de los trabajos presentados por los y las estudiantes de los Seminarios de Realidad Nacional. 
investigación. Se decanta la misma UCR-SO como la organización con la que más trabajos se han realizado.

Estos resultados muestran que en 9 casos la NC establecida es la 5: ¿De qué manera se pueden eliminar obstáculos y apoyar las iniciativas, avances y logros? Se evidencia que es de especial importancia comprender qué tanto saben, cómo valoran y en qué medida las iniciativas tomadas en distintos programas, proyectos y hasta currículos de estudio se muestran eficientes o no.

En el caso de la Biblioteca Pública de Palmares, por ejemplo, la funcionaria a cargo señalaba que era preocupante la concentración de la demanda en uno o dos de una serie de servicios que en este lugar se ofrecen. La organización podría cumplir mejor con su desempeño si comprendieran las razones de ello. De allí la consulta sobre el conocimiento que mostraban las personas sobre los distintos servicios que conforman la oferta total.

Se clasificaron con esta NC aquellas inquietudes que tienen que ver con el efecto de algunas condiciones (consumo de drogas, ambiente colegial, uso de video juegos y conocimientos de los padres sobre la sexualidad de sus hijos-as), dado que se estima que son condiciones que pueden afectar el éxito escolar y por supuesto su desarrollo integral como fin último del proceso formativo.

En 9 casos, la NC detectada fue la 4: ¿Cómo lograr una mayor inclusividad y dar respuesta a las necesidades de las personas? Es notoria la necesidad de favorecer una cultura no discriminante, que otorgue mayor posibilidad de acceso e integración de las personas al quehacer de la organización.

El caso de la indagación sobre la valoración de condiciones de estudio que rodean a los y las estudiantes de residencias de la UCR fue considerado en este mismo sentido, ya que se estableció que desatender este aspecto bien podría suponer un trato discriminatorio.

La NC 2 sólo se detectó en una investigación con la que se buscó establecer los diferentes recursos docentes, de investigación, de apoyo estudiantil, etc. que podían reconocerse al interior de la misma Universidad con el fin de buscar un mejor aprovechamiento de estos recursos en apoyo al programa Casita Infantil.

También, en un solo caso, la NC evidenciada fue la 1. La consulta estaba orientada a establecer si el estudiantado de la UCR-SO se identifica con la visión y los objetivos que persigue con el programa de formación humanista que debe aprobar todo el estudiantado de la UCR. La Universidad define como fundamental esta formación como moderador ético de una conducta profesional crítica y comprometida con el devenir del país. Sin embargo, surgió la duda de si el estudiantado comparte estos mismos objetivos.

La tabla 3 muestra que han sido 13 organizaciones de atención social con las que se han coordinado investigaciones. Destacan los trabajos realizados para el Hogar de Personas Adultas Mayores (PAM), la organización Musade que se especializa en realizar proyectos dirigidos al desarrollo integral y la atención de problemáticas de las mujeres y el Patronato Nacional de la Infancia (PANI). 
Tabla 3

Organización beneficiada, tema-problema abordado y Necesidad de Conocimiento establecidas en organizaciones e instituciones de atención social

\begin{tabular}{|c|c|c|}
\hline Organización & Tema - Problema & $\mathrm{NC}$ \\
\hline Hogar para PAM en San Ramón & $\begin{array}{l}\text { Dinámicas de trabajo interno para fomentar el desarrollo integral de las per- } \\
\text { sonas adultas mayores. (Cordero, Fonseca, Lobo, Quesada y Quesada, 2008) }\end{array}$ & 3 \\
\hline Hogar para PAM en San Ramón & $\begin{array}{l}\text { Desarrollo activo de las Personas Adultas Mayores del hogar de San Ramón. } \\
\text { (Acuña, Álvarez y Ledezma, 2011) }\end{array}$ & 4 \\
\hline Hogar para PAM en San Ramón & $\begin{array}{l}\text { Bournout en cuidadores-as de personas adultas mayores. (Castro, Suazo, } \\
\text { Vargas y Vargas, 2012) }\end{array}$ & 4 \\
\hline MUSADE & $\begin{array}{l}\text { Evaluación de los objetivos de los programas de apoyo a víctimas de violencia } \\
\text { intrafamiliar brindados en MUSADE. (Delgado, González, Lazo, López, } \\
\text { Sequeira, y Vargas, 2006) }\end{array}$ & 5 \\
\hline MUSADE & $\begin{array}{l}\text { Efectos psicosociales del concurso: Semilla de Arco Iris: MUSADE. (Corea, } \\
\text { Esquivel, Fuentes y Rodríguez, 2008) }\end{array}$ & 5 \\
\hline MUSADE & $\begin{array}{l}\text { MUSADE: Valoración de los servicios que ofrece en la Región de Occidente a } \\
\text { las usuarias. (Araya, Arce, Marín, Ramírez, y Rojas, 2011) }\end{array}$ & 5 \\
\hline IAFA San Ramón & $\begin{array}{l}\text { Variables psicosociales asociados al consumo de alcohol en personas de } 15 \\
\text { a } 30 \text { años de edad, en el cantón de San Ramón. (Badilla, Cubero, Méndez y } \\
\text { Rojas, 2009) }\end{array}$ & 4 \\
\hline IAFA San Ramón & $\begin{array}{l}\text { Factores comunales y familiares asociados al consumo de drogas. (Arias, } \\
\text { Chacón, Huertas, y Palma, 2011) }\end{array}$ & 4 \\
\hline PANI & $\begin{array}{l}\text { Conocimiento del programa "Adolescente Madre”. Evaluación de la campaña } \\
\text { radial. (Calvo, Hernández, Porras y Umaña, 2008) }\end{array}$ & 5 \\
\hline PANI Hogarcito en Santiago & $\begin{array}{l}\text { Virtudes Humanísticas. Desarrollo en personas menores en condición de aban- } \\
\text { dono albergadas. (Artavia, Bolaños, Ocampo, Rojas, Segura y Vargas, 2010) }\end{array}$ & 4 \\
\hline $\begin{array}{l}\text { Asociación pro- ayuda a la persona } \\
\text { con discapacidad (Palmares) }\end{array}$ & $\begin{array}{l}\text { Evaluación del programa: "Pro Ayuda a la persona discapacitada". } \\
\text { Conocimiento de la población meta sobre los servicios. (Brenes, Carranza, } \\
\text { Castro, Castro y Salas, 2008) }\end{array}$ & 5 \\
\hline $\begin{array}{l}\text { Centro de Atención Integral } \\
\text { (C.A.I), Sabana de San Ramón }\end{array}$ & $\begin{array}{l}\text { Autodescripción, estrategia de resolución de problemas y cuido del medio } \\
\text { ambiente en niños-as de preparatoria. (Elizondo, Granados, Morales, Quesada } \\
\text { y Villalobos, 2010) }\end{array}$ & 2 \\
\hline $\begin{array}{l}\text { Asociación Taller de Atención } \\
\text { Integral y Capacitación (ATAICA), } \\
\text { Grecia }\end{array}$ & $\begin{array}{l}\text { Formas de trabajo individual y grupal para la atención de poblaciones con } \\
\text { diferentes discapacidades psico-físicas. (Gómez, Gómez, Rodríguez, Sánchez } \\
\text { y Vega, 2012) }\end{array}$ & 3 \\
\hline
\end{tabular}

Elaboración del investigador a partir de los trabajos presentados por los y las estudiantes de los Seminarios de Realidad Nacional.

Casi en la mitad de los casos (5) la NC establecida fue la 5: ¿De qué manera se pueden eliminar obstáculos y apoyar las iniciativas, avances y logros? Vuelve a ser clara la importancia que tiene para estas organizaciones establecer si los proyectos que emprenden funcionan según se esperaba que lo hicieran. Establecer las valoraciones, conocimientos y hasta el logro de objetivos propuestos les permitiría conocer aspectos que lleven a su mejoramiento. Si, por el contrario, lo que se establece muestra que las cosas van bien, implicará una retroalimentación importante para seguir adelante.

Se evidencia que es de especial importancia comprender qué tanto saben, cómo valoran y en qué medida las iniciativas tomadas en distintos programas, proyectos y hasta currículos de estudio, se muestran eficientes o no.

También en 5 casos, la NC detectada fue la 4: ¿Cómo lograr una mayor inclusividad y 
dar respuesta a las necesidades de las personas? La preocupación se centró en estos casos en establecer las condiciones que rodean la vida de las personas y que pueden llevar a un deterioro en su desarrollo humano. El fin buscado es dar respuestas que lleven a satisfacer las necesidades experimentadas o superar alguna patología.

En 2 casos, la NC detectada fue la 3: ¿Cómo unificar la estrategia en los y las participantes para impulsar el ofrecimiento eficiente de los servicios? Valga resaltar en esto la necesidad implícita de actualización sobre distintos y alternativos métodos y técnicas para un trabajo más eficiente. En concreto, se requiere conocer cómo se pueden hacer las cosas de mejor manera.

Sólo en 1 caso, la NC determinada fue la 2: ¿Cómo formar equipo y aprovechar las habilidades y las competencias de los y las integrantes a diferentes niveles? La investigación realizada estuvo dirigida a establecer las características personales que están detrás de las actitudes hacia el cuido del medio ambiente, por lo que se busca con ella conocer la manera de fomentar las habilidades o mejores condiciones personales para lograr un empeño conjunto que es lo que se requiere para la buena marcha de un objetivo común.

La tabla 4 da cuenta de que han sido 11 las organizaciones relacionadas con la gobernabilidad local las beneficiadas. Sobresale entre ellas la Municipalidad de San Ramón para la que se han realizado 6 de estas investigaciones, así como la Guardia Civil con 3 de éstas.

Tabla 4

Organización beneficiada, tema - problema abordado y Necesidad de Conocimiento establecida en organizaciones relacionadas con la gobernabilidad local

\begin{tabular}{|c|c|c|}
\hline Organización & Tema - Problema & $\mathrm{NC}$ \\
\hline Municipalidad de San Ramón & $\begin{array}{l}\text { Opinión de los jóvenes del cantón central de San Ramón acerca de las activi- } \\
\text { dades deportivas - recreativas impulsadas por el gobierno local para la promo- } \\
\text { ción de la salud. (Campos, Carranza, Vargas y Castillo, 2007) }\end{array}$ & 5 \\
\hline Municipalidad de San Ramón & $\begin{array}{l}\text { Procedimientos y criterios utilizados en construcciones de áreas recreativas } \\
\text { y urbanizaciones en la RCO para el cumplimiento de la ley } 7600 \text {. (Corrales, } \\
\text { Madrigal, Rodríguez, Sanabria y Soto, 2007) }\end{array}$ & 4 \\
\hline Municipalidad de San Ramón & $\begin{array}{l}\text { Dificultades organizacionales que enfrenta la Municipalidad de San Ramón } \\
\text { para la promoción de programas recreativos dirigidos a poblaciones jóvenes. } \\
\text { (Alfaro, Chaves, Murillo, Vásquez y Watson, 2008) }\end{array}$ & 2 \\
\hline Municipalidad de San Ramón & $\begin{array}{l}\text { Evaluación del Proyecto de erradicación de precarios en Bajo Tejares de la } \\
\text { Municipalidad de San Ramón. (Chávez, Lizano, Morera y Rojas, 2008) }\end{array}$ & 5 \\
\hline Municipalidad de San Ramón & $\begin{array}{l}\text { Dificultades en la implementación del lenguaje inclusivo en la documentación } \\
\text { de la Municipalidad de San Ramón. (González, Sancho, Ruíz y Valle, 2008) }\end{array}$ & 4 \\
\hline Municipalidad de San Ramón & $\begin{array}{l}\text { Necesidades femeninas en proyectos urbanísticos. San Ramón. (Méndez, } \\
\text { Núñez, Torres y Villegas, 2008). }\end{array}$ & 4 \\
\hline Guardia Civil de San Ramón & $\begin{array}{l}\text { Relación entre condiciones físico ambientales de trabajo y la auto-valoración } \\
\text { del desempeño en Guardias Civiles de San Ramón. (González, Porras, Rojas } \\
\text { y Salazar, 2009) }\end{array}$ & 5 \\
\hline Guardia Civil de San Ramón & $\begin{array}{l}\text { Diseño urbanístico y sentido de seguridad en personas que realizan actividades } \\
\text { habituales en el cantón de San Ramón. (Chavarría y Vargas, 2011) }\end{array}$ & 4 \\
\hline Guardia Civil de San Ramón & $\begin{array}{l}\text { Cumplimiento de objetivos de los programas de prevención comunitaria. } \\
\text { (Badilla, Mora, Rodríguez y Salas, 2011) }\end{array}$ & 5 \\
\hline Comisión de emergencias. Grecia & $\begin{array}{l}\text { Evaluación organizativa de la Comisión de Emergencias de Grecia. (Barrientos, } \\
\text { Cubero, Salazar y Villalobos, 2008) }\end{array}$ & 2 \\
\hline $\begin{array}{l}\text { Corte Suprema de Justicia. San } \\
\text { Ramón }\end{array}$ & $\begin{array}{l}\text { Eficiencia percibida por los y las usuarias del servicio de Resolución } \\
\text { Alternativa de Conflictos. San Ramón. (Arroyo, Funes, Hérnandez y Ramírez, } \\
\text { 2009) }\end{array}$ & 5 \\
\hline
\end{tabular}

Elaboración del investigador a partir de los trabajos presentados por los y las estudiantes de los Seminarios de Realidad Nacional. 
En 5 casos, la NC revelada fue la 5. En tres de ellos se asocian los posibles obstáculos a factores externos lo que les lleva a preguntarse por la opinión o valoración de las poblaciones meta, tal es el caso del servicio de Resolución Alternativa de Conflictos que se ofrece en la Corte Suprema de Justicia de la región. Una manera de percatarse de las dificultades que puede enfrentar un programa de este tipo es consultar precisamente a la población que recibe el servicio sobre las fortalezas y debilidades del mismo. En el caso del estudio realizado con Guardias Civiles, tales obstáculos son ubicados dentro de la misma organización al preguntarse sobre la asociación entre desempeño y las condiciones físicas y ambientales en que les corresponde realizar el trabajo.

En 4 de estos casos, la NC que se acusa es la 4 , relacionada con las preocupaciones por la inclusividad y las necesidades de las personas. En el caso de la investigación sobre el diseño urbanístico y el sentimiento de inseguridad, el interés era conocer si las formas y el estado del diseño arquitectónico de algunos sectores del cantón de San Ramón se asociaban con un aumento de este sentir, lo que llevaría a las personas a hacer un retiro estratégico de estos sitios, lo cual obviamente les cierra espacios de tránsito y actividad.

Conviene resaltar que, en 2 casos, la NC detectada fue la 2 , especialmente en el sentido de "formar equipo". Se desprende de este interés que efectivamente la realización de una tarea organizada enfrenta diversas dificultades, sobre todo de índole actitudinal. Esta es una de las NC en que se evidencia una mayor conciencia de las dificultades del desempeño organizacional como proceso humano. En el caso de la Comisión Local de Emergencias, era notorio que, aunque los participantes tienen un cometido común, el problema organizativo radicaba en la falta de participación y quizá compromiso con que cada quien asumía su rol.

La tabla 5 muestra las 8 organizaciones encargadas de atender temáticas de salud. Programas de la Caja Costarricense de Seguro Social (CCSS), el hospital de San Ramón y dos Equipos Básicos de Atención Integral en Salud (EBAIS) han sido los beneficiarios de estas investigaciones.

Tabla 5

Organización beneficiada, tema-problema abordado y Necesidad de Conocimiento establecida en organizaciones relacionadas con temas de salud

\begin{tabular}{llc}
\hline Organización & Tema - Problema & NC \\
\hline $\begin{array}{l}\text { Comités de nutrición y } \\
\text { salud (CCSS) }\end{array}$ & $\begin{array}{l}\text { Prácticas Educativas para la promoción de la salud en los Centros Educativos de } \\
\text { Primaria de la RCO. (Araya, Méndez, Ponce y Varas, 2007) }\end{array}$ & 3 \\
\hline CCSS: Naranjo & $\begin{array}{l}\text { Impacto del programa "Ejercicios v Recreación. Estilos de vida saludable al Adulto } \\
\text { Mayor" en su calidad de vida. (Arce, Cascante, Cordero, Cubero y Mora, 2007) }\end{array}$ & 4 \\
\hline $\begin{array}{l}\text { Ministerio de Salud, San } \\
\text { Ramón }\end{array}$ & $\begin{array}{l}\text { Organizaciones que utilizan procesos de producción con tecnologías limpias. } \\
\text { Conocimiento de los habitantes de la RCO. (Chaves, Cisneros, Murillo y Zamora, }\end{array}$ & 5 \\
\hline Ministerio de Salud, San & Implementación del Manual de Atención Integral en la Salud de los Niños (as) en el \\
Ramón & $\begin{array}{l}\text { Escenario Escolar en la Región de Occidente. (Calvo, Chacón, Hernández, Murillo, } \\
\text { Novo, Rodríguez y Reyes, 2009) }\end{array}$ & 7 \\
\hline Hospital de San Ramón & $\begin{array}{l}\text { Conocimiento de derechos en madres primerisas. Hospital de San Ramón. (Barrantes, } \\
\text { Castro y Ulate, 2009) }\end{array}$ \\
\hline Hospital de San Ramón & $\begin{array}{l}\text { Ventajas y desventajas de la migración de combustible diesel al gas licuado de petróleo } \\
\text { (GLP). (Araya, Arce, Arguedas, Chavarría y Johnson, 2012) }\end{array}$ & 6 \\
\hline EBAIS Tacares Grecia & Valoración del desempeño que hacen los y las usuarias de los y las funcionarias del & 5 \\
& EBAIS de Tacares de Grecia. (Araya, Elizondo, Mora y Umaña, 2008) & 5 \\
\hline EBAIS Piedades Sur & $\begin{array}{l}\text { Valoración del desempeño que hacen los y las usuarias de los y las funcionarias del } \\
\text { EBAIS de Piedades Sur en San Ramón. (Delgado, Quesada y Salazar, 2012) }\end{array}$ & 5 \\
\hline
\end{tabular}

Elaboración del investigador a partir de los trabajos presentados por los y las estudiantes de los Seminarios de Realidad Nacional. 
En 3 de estos trabajos, la NC acusada fue la 5. Igual que en casos ya comentados, los estudios evaluativos han estado orientados a establecer aquellos aspectos que pueden dar al traste con un trabajo eficiente.

En un sentido contrario, pero siempre dentro de la misma NC, la investigación sobre el conocimiento que tienen las y los habitantes de la RCO sobre las empresas que implementan procesos de producción mediante el uso de tecnologías limpias evidencia el interés que en el programa de Promoción de la Salud (CCSS) se tiene de premiar de alguna manera estas iniciativas y apoyar así que lo sigan haciendo, y quizá motivar a otras para que tomen esta misma iniciativa.

En dos casos, la NC detectada fue la 4. En ambos, se buscó determinar si se respondía eficientemente a las necesidades que tienen las poblaciones consideradas. En el caso de las madres primerizas, se consideró que no bastaba que existieran derechos orientados a garantizar una mejor atención en el momento del alumbramiento, pues, a pesar de que tales derechos existen, en los fundamentos justificatorios de la investigación se daba cuenta de múltiples quejas por la atención recibida. El interés por tanto radicó en determinar aquellos aspectos que podían atenderse para garantizar que las múltiples necesidades que experimentan estas mujeres fuesen consideradas efectivamente.

La NC 3 sólo fue reconocida en un caso. En esta investigación, el interés final estaba orientado a conocer sobre las mejores prácticas docentes asociadas a un mayor fomento de actitudes de autocuidado en la población estudiantil.

Lo mismo sucedió con la NC 7 en cuya investigación se esperaba determinar la forma en que se estaba llevando a cabo la implementación del Manual de Atención Integral en la Salud de los y las Niñas en cuatro escuelas de la región con el fin de darle el apoyo que se requiriera para un mayor impulso.

En todo el recorrido que hemos hecho, no se había detectado una NC 6, como en el caso que se muestra en la tabla 5. El interés de esta indagación sobre las ventajas y desventajas de la migración de un combustible a otro da muestras de la necesidad que en un momento determinado pueden experimentar en una organización de cerrar un capítulo y abrir otro que lleve a su mejor desenvolvimiento.

La tabla 6 muestra las organizaciones productivas con las que se han coordinado investigaciones, 7 en total. El tema agrícola y la forma de organización cooperativa es lo que se acusa con mayor predominio.

Tabla 6

Organización beneficiada, tema-problema abordado y Necesidad de Conocimiento establecida en organizaciones productivas

\begin{tabular}{llc}
\hline Organización & Tema - Problema & NC \\
\hline Coope Bajo Tejares & $\begin{array}{l}\text { Participación y autoestima en mujeres integrantes de la cooperativa Coope-Bajo Tejares. } \\
\text { (Alfaro, Chaverri, Navarro, Oviedo y Rodríguez, 2007) }\end{array}$ & 4 \\
\hline Coope Bajo Tejares & $\begin{array}{l}\text { Necesidades psicosociales en la población infantil (0-5 años) de las madres que integran la } \\
\text { Cooperativa Bajo Tejares. (Díaz, Jiménez, Pérez, Prendas y Santamaría, 2007) }\end{array}$ & 4 \\
\hline CONARROZ & $\begin{array}{l}\text { Necesidades de capacitación en la gestión de Agro-negocios, en productores de arroz. } \\
\text { (Alfaro, Barrantes, Bolaños, Castro, Soto y Zamora, 2007) }\end{array}$ & 3 \\
\hline MAG-Grecia & $\begin{array}{l}\text { Los Biodigestores: Conocimientos sobre la tecnología en porcicultores de Grecia. } \\
\text { (Campos, González, Hernández y Rodríguez, 2008) }\end{array}$ & 5 \\
\hline CoopeTacares & $\begin{array}{l}\text { Satisfacción de los y las usuarias con los servicios que brinda la cooperativa CoopeTacares. } \\
\text { (Campos, Ramírez, Román, Salazar y Vega, 2008) }\end{array}$ & 5 \\
\hline $\begin{array}{l}\text { Grupo de agricultores: } \\
\text { Forjadores del Futuro }\end{array}$ & $\begin{array}{l}\text { Potencialidades para la comercialización de productos orgánicos según comerciantes de } \\
\text { Zarcero, Naranjo, San Ramón y Grecia. (Rodríguez, Salazar, Varela y Zamora, 2009) }\end{array}$ & 5 \\
\hline $\begin{array}{l}\text { Productores de Café de } \\
\text { la RCO }\end{array}$ & $\begin{array}{l}\text { Resistencia campesina. Características personales de productores de café que se mantienen } \\
\text { en esta actividad. (Carr, Hernández, Hidalgo, Méndez y Solano, 2010) }\end{array}$ & 2 \\
\hline
\end{tabular}

Elaboración del investigador a partir de los trabajos presentados por los y las estudiantes de los Seminarios de Realidad Nacional. 
La NC más frecuente es la 5, en tres casos. El conocimiento y la valoración de las poblaciones meta vuelven a ser considerados posibles obstáculos para el avance eficiente de una propuesta. En el caso de la investigación sobre las potencialidades para la comercialización de productos orgánicos, el interés de la organización radicaba en revelar esos posibles obstáculos que su iniciativa productiva encuentra en los comercios de la RCO.

En 2 casos, la NC fue la 4, ambos relacionados con las necesidades del desarrollo (psicosociales y autoestima) de las poblaciones vinculadas con la organización.

El caso en que la NC detectada fue la 2, llama especialmente la atención en el sentido de que el interés se concentra en "aprovechar las competencias y habilidades" de las personas para alcanzar fines propuestos, en este caso salvaguardar la producción cafetalera de la región.

A pesar de que los temas-problema relacionados con problemáticas medio ambientales, en las investigaciones reportadas en los últimos 7 años, sólo se tiene registro de una organización especializada en esta temática, como muestra la tabla 7.

Tabla 7

Organización beneficiada, tema-problema abordado y Necesidad de Conocimiento establecida en organizaciones ambientalistas

\begin{tabular}{llll}
\hline Organización & Tema - Problema & NC \\
\hline Colectivo Femenino Rescatando & Mitos y creencias acerca de la actividad del reciclaje en las comunidades & \\
Nuestra Ecología (COFERENE) & de Los Cipreses y Los Parques en San Ramón. (Arce, Gaitán, Mora y & 5 \\
& Vargas, 2011) & \\
\hline
\end{tabular}

Elaboración del investigador a partir de los trabajos presentados por los y las estudiantes de los Seminarios de Realidad Nacional.

La NC que subyace a esta investigación es la 5, ya que esta organización intuye que la baja iniciativa por reciclar que muestran algunas comunidades o personas podría explicarse por falsas creencias que tengan las personas sobre esta actividad. De ser así, se trataría de corregir tales ideas erróneas mediante informaciones válidas lo que llevarían a una superación del obstáculo que enfrenta la organización.

Como resumen de todo lo anterior, en la tabla 8 se muestran, en orden de frecuencia descendente, las NC subyacentes a los estudios realizados según el sector al que pertenecen las organizaciones.

Tabla 8

Matriz: Total de investigaciones realizadas, según sector y Necesidad de Conocimiento (NC)

\begin{tabular}{|c|c|c|c|c|c|c|c|}
\hline Sector & Educación & $\begin{array}{c}\text { Atención } \\
\text { Social }\end{array}$ & $\begin{array}{c}\text { Gobierno } \\
\text { Local }\end{array}$ & Salud & Productivo & Ambiente & Total \\
\hline \multicolumn{8}{|l|}{$\mathrm{NC}$} \\
\hline 5 & 9 & 5 & 5 & 3 & 3 & 1 & 26 \\
\hline 4 & 9 & 5 & 4 & 2 & 2 & $*$ & 22 \\
\hline 2 & 1 & 1 & 2 & $*$ & 1 & * & 5 \\
\hline 3 & $*$ & 2 & $*$ & 1 & 1 & $*$ & 4 \\
\hline 6 & $*$ & $*$ & $*$ & 1 & $*$ & $*$ & 1 \\
\hline 7 & $*$ & $*$ & $*$ & 1 & $*$ & $*$ & 1 \\
\hline 1 & 1 & $*$ & $*$ & $*$ & $*$ & $*$ & 1 \\
\hline 8 & $*$ & $*$ & $*$ & $*$ & $*$ & $*$ & 0 \\
\hline Total & 20 & 13 & 11 & 8 & 7 & 1 & 60 \\
\hline
\end{tabular}

Elaboración del investigador a partir de los trabajos presentados por los y las estudiantes de los Seminarios de Realidad Nacional. 
Los resultados muestran que:

1. La eliminación de obstáculos para realizar un trabajo más eficiente (NC 5), es la que decanta con mayor frecuencia (26 casos).

2. Alcanzar una mayor inclusividad y satisfacción de necesidades para el DHI de personas $\mathrm{y}$ grupos (NC 4), es la segunda en frecuencia (22 casos).

3. Formar equipos de trabajo, a la vez que se aprovechan las habilidades y competencias de los y las participantes ( $\mathrm{NC} 2$ ), es la que sigue (5 casos).

4. Unificar una visión estratégica (NC 3) se detectó en 4 casos.

5. Las NC 1 (¿Cuáles son las motivaciones de las personas para lograr los objetivos de la organización?), 6 (¿Cómo finalizar etapas y abrirse a otras nuevas?) y 7 (¿De qué manera promover y fomentar la determinación y la perseverancia alrededor de las acciones en curso?) sólo contaron con una investigación.

Además de los pocos intereses que muestran la gran mayoría de las NC, llama la atención que la NC 8 no haya aflorado en ninguna investigación. Ella se refiere a la necesidad de conocer la manera de fomentar nuevos liderazgos para favorecer el desarrollo de la cultura organizacional.

\section{Discusión}

El meta-análisis de los 60 trabajos de investigación realizados muestra que en las organizaciones de la Región Central de Occidente privan las NC dirigidas a determinar: cómo eliminar obstáculos para el trabajo eficiente y cómo alcanzar una mayor inclusividad y satisfacción de necesidades de las personas.

En el primer caso, se pudo establecer que con tal necesidad de conocimiento se busca reconocer, en la mayoría de los casos, aquellos factores que dificultan que las iniciativas organizacionales cuajen en un logro efectivo de los objetivos. En consecuencia, existe al menos la intuición de que el proceso no está funcionando como se esperaría. Los datos justificatorios se basan en gran medida en señalar quejas y malestares de los y las usuarias de los servicios que la organización brinda, pero también en el hecho evidente de que las metas definidas no se están logrando como debieran, por ejemplo no alcanzar al número de personas propuesto, o no lograr que desarrollaran las actitudes que se les requería, o no vislumbrar los efectos en la salud que se esperaba, etc.

Los estudios realizados en este sentido buscan en gran medida dar la palabra a los y las usuarias con el fin de "tener una mirada desde fuera" sobre el funcionamiento interno de la organización. Ello nos parece importante en la medida que los resultados dan pie a posteriores y más profundas consultas sobre el desempeño organizacional, pues lleva inevitablemente a "dirigir la mirada hacia dentro". Si estos resultados se toman con un sentido auto-evaluativo debieran constituirse en un importante insumo para abundar en el desempeño más consuetudinario de la organización, lo cual es sin duda una gran oportunidad para estimular lo que funciona bien y corregir lo que se deba.

Con respecto a la $\mathrm{NC} 4$, es importante hacer algunos señalamientos. No creemos fortuito que sea en los sectores de educación, atención social y gobierno local donde más aflora esta $\mathrm{NC}$, sobre todo en los dos primeros, pues en gran medida los temas de satisfacción de necesidades y de inclusión social les son inherentes.

Es importante denotar que, sin importar el sector de que se trate, existe una importante preocupación por los problemas y/o dificultades que viven las personas de la región. A diferencia de la $\mathrm{NC}$ anterior, con ésta se busca establecer los problemas en el desempeño organizacional al dirigir la atención a las personas mismas, a su desarrollo integral y, en fin, hacia su bienestar.

En el fondo, con esta NC se revela que en estas organizaciones ronda un sentido de incertidumbre, y si se quiere de incapacidad para enfrentar con un grado aceptable de éxito incidir en la dramática situación de conflictividad social y psicológica que viven las personas hoy día. Problemas como los prejuicios y la exclusión social, las patologías sociales, el acceso a servicios, la vulnerabilidad social, patologías laborales, etc., son dramas que en vez de reducirse, crecen a los ojos de todos y todas, sobre todo de aquellas personas que son parte de organizaciones que por 
su naturaleza tienen como parte de sus tareas la atención y prevención de tales problemas.

Con esta NC, se muestra además, por un lado el interés de las y los funcionarios que laboran en estas organizaciones de llevar soluciones efectivas a sus poblaciones meta, mientras que por el otro la desazón recurrente de no lograrlo. Esta es quizá la NC que mejor refleja la inercia que caracteriza el desempeño de muchas organizaciones de nuestro país. La falta de respuestas satisfactorias a semejantes preguntas no puede más que generar en estas personas una suerte de inmovilismo y pesadez al debatirse entre el deber hacer que le marcan los objetivos de la organización y el no saber cómo hacerlo.

Por lo dicho, debe considerarse como algo muy positivo que aún persistan estas NC. Peor sería si ni eso se diera.

En el orden de frecuencia, las NC 2 y 3 se presentaron en 5 estudios la primera y en 4 la segunda. Nos parece importante señalar que en el análisis de estas NC hubo dificultades para establecer cuándo se trataba de una y cuándo de la otra. Formar equipos de trabajo, a la vez que se aprovechan las habilidades y competencias de los y las participantes (NC 2) parece confundirse en casos concretos con el interés por conocer cómo unificar una estrategia conjunta para el logro de objetivos en estas personas (NC 3).

Entendemos que la NC 3 está dirigida a reconocer sobre modelos de trabajo que hubiesen mostrado ser eficientes en el logro de productos concretos. Pero también deja ver el interés por establecer si los modelos en ejecución son útiles, sustentados y coherentes, entre los distintos componentes epistemológicos, teóricos y metodológicos, para alcanzar los objetivos organizacionales.

Consideramos que esto es de vital importancia para las organizaciones, y con el hecho de planteársela se da un paso más allá a lo discutido en cuanto a las NC 5 y 4 . Geibler y Hege (1997) afirman que, para casos de organizaciones dirigidas a la atención social, el divorcio entre los fundamentos epistemológicos de un modelo de trabajo, las teorías y los métodos, explica en gran medida la desorientación que parecen mostrar muchas dinámicas organizacionales, a la vez que se asocia con la desmotivación y hasta incredulidad que parece guiar las formas de trabajo de muchos y muchas funcionarias.

La relación teoría-práctica (Geibler y Hege, 1997), o si se quiere concepción-ejecución (Guijarro, 1975) en el trabajo es lo que brinda el sentido de integralidad y utilidad a toda actividad. Cuando estos niveles no se integran en la misma vida laboral, y más bien se les separa, se pueden provocar diferentes grados de enajenación y desorganización, como los que al parecer se busca subsanar con esta NC.

Distinto es con la NC 2 que busca responder a la inquietud de cómo hacer sinergia entre las personas y aprovechar lo que cada quien puede aportar a un trabajo de conjunto. Aunque esta consulta puede ser tan clara como la que se muestra en aquellas investigaciones dirigidas a realizar un inventario de recursos y a preguntarse sobre las actitudes que imposibilitan que las personas lleguen a acuerdos, también se muestra en consultas un poco más difusas como las dirigidas a establecer rasgos de personalidad o actitudinales entre personas que muestran comportamientos esperados o deseados contra comportamientos inesperados o indeseados para alcanzar metas comunes.

No es extraño, entonces, que las NC 2 y 3 parezcan confundirse entre sí ya que ambas tratan de alcanzar el objetivo común de un trabajo unificado. Si la NC 3 se pregunta por el paradigma, por así decirlo, la NC 2 lo hace por las competencias entre las personas para lograr trabajar en grupo; en ello radica su diferencia.

No es interés de este trabajo establecer ningún tipo de correlación entre las distintas NC. Sin embargo, no podemos dejar de decir que nos parece que estas dos NC están vinculadas de una estrecha manera, sin pretender establecer ninguna relación causal entre ellas.

También sucumbimos a la avidez por fundar una hipótesis, sólo para que sea considerada en otros esfuerzos. El hecho de que la frecuencia de estudios dirigidos a establecer las NC 2 y 3 haya decaído tan significativamente no debiera verse a la ligera, ya que nos parecen ser de un montante reflexivo mayor, y de una más y profunda interpelación al quehacer de la organización.

No es lo mismo preguntarse por acciones o temas específicos para que las cosas funcionen 
mejor, caso de las NC 4 y 5 , que preguntarse por las formas de trabajo internas, de las que al final depende todo ejercicio exterior.

En todo caso, la NC 2 revela el interés por lograr la sinergia entre las personas para que el grupo se enriquezca de las habilidades y competencias que cada quien aporta. Resalta en los estudios la necesidad de conocer la forma de "desentrabar" las relaciones interpersonales para que la organización funcione. La idea de Bleger (1985) de que el trabajo óptimo de un grupo se logra al establecer la "mayor unidad en la tarea (objetivo)" frente a la "mayor diversidad de posturas individuales" parece dar pie a la pregunta de: ¿en qué medida la tarea o los objetivos de las personas les son comunes? O si se quiere, ¿cuáles son los objetivos que persiguen algunos o algunas funcionarias cuando se trata de trabajar en grupo?

Claramente, se haría necesaria la diferenciación entre los objetivos de la organización y los objetivos de las personas, pero eso sería parte de otros debates ajenos al presente.

La NC 6, sobre la forma de cerrar etapas y abrirse a otras, sólo fue posible distinguirla en un estudio. Con esta NC se revela el interés por conocer la forma de sustentar y/o producir las informaciones que se requieren para la toma de decisiones. Para decirlo coloquialmente, se trata de contestar a la consulta ¿cómo conjurar creencias con el aporte de datos? Por lo tanto, con esta $\mathrm{NC}$ se revela un mayor interés técnico - científico de que sea lo razonable lo que guíe la decisión.

A pesar de que la consulta bien podría estar dirigida a establecer un método para persuadir o llevar a funcionarios y funcionarias de una etapa a otra con el mayor "control de daños" posible, lo cierto es que la única consulta realizada no iba encaminada en este sentido.

El interés de la investigación sobre migración de un combustible a otro, nada menos que en el caso de un hospital, tuvo como guía formar una lista de cotejo donde se establecieran las ventajas y desventajas de cada combustible según un conjunto de variables, por ejemplo económicas, de seguridad, accesibilidad, etc.

El reto está en buscar formas de razonar y persuadir, por lo que la apelación de fondo es a que las jefaturas tomen decisiones fundadas en criterios verificables y no en supuestos subjetivos.

De igual forma, la NC 7, sobre la manera de fomentar la determinación y perseverancia de las acciones en curso, se encontró sólo en una investigación realizada para el Programa de Promoción de la Salud, del Ministerio de Salud de San Ramón. Con este trabajo, se buscó establecer la forma en que está siendo implementado, por los y las educadoras de diferentes instituciones escolares de la región, un manual de atención integral de la salud de los y las estudiantes.

Según las justificaciones para realizar esta investigación, los y las docentes que participan del proyecto no lo implementan con igual ímpetu o suceso. Más que diferenciar quién lo hace bien y quién no, se trataba de conocer cuáles son las motivaciones que llevan a que los y las participantes asumieran la tarea con distintos grados de compromiso. La información que se desprende de esta consulta se constituiría en un insumo importante para promover acciones tendientes a aumentar la motivación en quienes se muestre disminuida.

La NC 1 sólo se presentó en el caso del estudio relacionado con la valoración que hacen los y las estudiantes de la UCR-SO sobre la formación humanista que deben cursar como parte del currículo de cada carrera en la universidad. Los estudiantes Noé Ramírez y Steven Rodríguez (2010) propusieron realizar esta indagación al Sistema de Educación General (SEG) debido a que, en su dicho, dentro del estudiantado se discute reiteradamente la pertinencia de todo el conjunto de cursos que, sin ser parte de los que contempla el currículo de su propia carrera, deben cursar como requisito de todo el plan de estudios.

Tal iniciativa contó con el beneplácito del SEG, dado que sumaban a tales inquietudes el interés manifiesto por realizar una evaluación sobre la pertinencia y actualización de este conjunto de cursos al interior de la Sede de Occidente.

Dado que la NC 1 pone en cuestionamiento la identificación que guía el quehacer de las personas que conforman una organización con la visión y objetivos que se propone alcanzar, pensamos que refleja de forma aún incipiente el debate sobre los perfiles profesiográficos al que aspiran 
como formación quienes conforman la Universidad en el contexto de las nuevas demandas que emanan del proceso de globalización.

Como expusimos en nuestro fundamento conceptual, la globalización impuesta, o desde arriba, genera, desde años atrás, presiones a las organizaciones, sobre todo si son de índole estatal, para que cambien a favor de ciertos valores. Dijimos que es notorio el fomento actual de valores prácticos e instrumentales frente a valores humanistas, y la Universidad no escapa a ello.

Si la Universidad de Costa Rica pretende seguir por el derrotero de una formación integral, crítica y comprometida con el bien común, humanista en pocas palabras, debiera considerar que es prioritario contemplar esta $\mathrm{NC}$ con el fin de que se haga todo esfuerzo por lograr fortalecer esta visión institucional para que sea parte de sus códigos culturales e irrigar así al mayor número de personas posible, dentro y fuera de ella.

Por último, la $\mathrm{NC} 8$, orientada a conocer sobre nuevas formas de liderazgo que promuevan la evolución de la cultura de la organización, no se reconoció en ninguna de las investigaciones.

Creemos que esto tampoco es fortuito y se explica fundamentalmente por el hecho de que los líderes no suelen consultar sobre sí mismos, ni sobre la forma en que hacen las cosas y menos sobre su filosofía de vida, misma que promueven, consciente o inconscientemente, para que se constituya en parte importante de la cultura organizacional (Cable y Furst, 2008).

El cambio en los liderazgos y el remozamiento de las metas organizacionales no es una iniciativa que promuevan fácilmente quienes detentan los escaños más elevados del organigrama. Es muy frecuente que la visión, misión y metas de la organización (Davis y Newstrom, 2000), se corresponda con la particular forma de ser y de pensar de sus líderes.

Es clara la razón por la que esta $\mathrm{NC}$ se niega a aflorar, pero es innegable que es en su abordaje donde se generan los mayores réditos en todo empeño de evolución organizacional, ya que con ello se posibilitaría que otras personas, con diferentes visiones de mundo y competencias administrativas, abonen a un mejor desempeño de la organización (Arras y Jáquez, 2008;
Cable y Furst, 2008; Davis y Newstrom, 2000; Robbins, 1987).

\section{Balance final}

Llegados a este punto, es importante realizar dos últimas reflexiones que se desprenden de este trabajo.

La primera es con respecto a las categorías que denominamos "necesidades de conocimiento" (NC). Es importante señalar que esta propuesta requiere aún de mayores fundamentos y debates teóricos que den cuenta de su utilidad como constructo y como insumo para mejorar el desempeño de las organizaciones.

Llamó nuestra atención el artículo de Predişcan y Săcui (2011) sobre las oportunidades para reducir la "resistencia al cambio" en las organizaciones. Esta problemática es tratada con mucha regularidad cada vez que se habla de la implementación de nuevas tecnologías, formas de trabajo o redefinición de metas, etc. Es decir, se sabe que la resistencia al cambio existe como realidad organizacional (Robbins, 1987; Davis y Newstrom, 2000), así como diversas propuestas para afrontarla, pero en el artículo de marras las resume y las ubica como acciones a emprender en diferentes niveles del organigrama.

De nuestra parte, lo que hicimos fue dar un paso atrás para verlas, ya no como acciones, sino como intuiciones que pueden subyacer a las distintas consultas que buscan respuesta al interior de las organizaciones. Por hacer un símil con la medicina, sólo es posible proponer acciones remediales si la etiología del problema está claramente establecida. En otras palabras, ser consciente de ciertos síntomas no implica necesariamente conocer la patología.

A la concepción de NC le subyace la hipótesis, que parece comprobarse apenas inicialmente, de que: a las preguntas que se hacen los y las funcionarias sobre el desempeño organizacional les subyacen otras que tienen que ver con la propia dinámica humana que en ellas se da. Detrás de la pregunta reiterada que se hace en varios estudios sobre las razones de que los y las usuarias de ciertos servicios se quejen, está otra, no del todo consciente, sobre las razones por 
las cuales el trabajo en equipo no logra impactar positivamente a esta población, por ejemplo.

Quedaría por realizar más y controladas investigaciones que tomaran como base la propuesta que en este trabajo se hace con respecto a las NC. Los resultados de trabajos de este tipo permitirían precisar el debate teórico sobre cada una de estas necesidades, ya sea para mantenerlas, redefinirlas o agruparlas de tal modo que resulten más útiles, tanto para la realización de futuras investigaciones, como para la implementación de las medidas correctivas que se correspondan con ellas y coadyuven al mejor funcionamiento de las organizaciones.

El segundo aspecto a resaltar tiene que ver con el papel que despliega la Universidad de Costa Rica en la RCO.

Llama en primera instancia la atención que muchos de los trabajos realizados se hagan para la misma sede universitaria. A pesar de que se entiende que existe un claro componente de comodidad y accesibilidad para ello, no deja de contravenirse con esto el compromiso y objetivo de la regionalización universitaria de coadyuvar en la mayor medida posible al desarrollo integral del conjunto de actores que componen la red societal de cada región.

Para lograr que estos trabajos se reviertan cada vez más a las organizaciones de la región, consideramos importante fomentar una mayor y efectiva coordinación entre las instancias universitarias (investigación, acción social y docencia) y garantizar así que las investigaciones que se realizan como parte de cada curso se inserten en programas, proyectos de investigación o los TCU vigentes en cada zona.

Son innumerables las horas y esfuerzos que dedican, tanto el cuerpo docente como el estudiantado, en realizar investigaciones que no cuentan con suficiente base justitifatoria y para las que, en la mayor parte de ellas, no se da seguimiento alguno. Distinto sería si las consultas que buscan ser evacuadas con estos trabajos se desprendieran de la labor continuada de un TCU, por ejemplo. En tal caso se conocería claramente, por un lado la importancia de realizar la investigación, y por el otro el aporte concreto que se da al progreso de tal proyecto. Reiteramos con Bleger (1985) que este sería conocimiento "vivo" y por lo tanto útil, que beneficia tripartitamente a la organización regional, al y la estudiante y a la Universidad.

Coordinaciones de esta índole facilitarían dar continuidad a los procesos dado que habrían personas a cargo de ello. Los subgrupos de estudiantes se dirigirían a estas y estos funcionarios para que les indiquen qué necesidades de conocimiento tienen; y a ellos se dirigiría el informe final de cada trabajo. Una investigación seguiría a otra en una suerte de orden o lógica marcada por la dinámica de un proceso.

Una tan encomiable labor como la que proponemos, tendría mayores expectativas de volverse realidad si las NC 1 y 8 aflorarán fidedignamente en la propia organización universitaria.

\section{Referencias bibliográficas}

Acuña, L.; Álvarez, F. y Ledezma, Y. (2011). Desarrollo activo de las Personas Adultas Mayores del hogar de San Ramón. Universidad de Costa Rica. (Trabajo sin publicar del curso Seminario de Realidad Nacional).

Alfaro, O.; Barrantes, M.; Bolaños, A.; Castro, K.; Soto, M. y Zamora, J. (2007). Necesidades de capacitación en la gestión de Agro-negocios, en productores de arroz. Universidad de Costa Rica. (Trabajo sin publicar del curso Seminario de Realidad Nacional).

Alfaro, R.; Chaverri, L.; Navarro, K.; Oviedo, M.; y Rodríguez, A. (2007). Participación y autoestima en mujeres integrantes de la cooperativa Coope-Bajo Tejares. Universidad de Costa Rica. (Trabajo sin publicar del curso Seminario de Realidad Nacional).

Alfaro, R.; Chaves, O.; Murillo, A.; Vásquez, E. y Watson, Y. (2008). Dificultades organizacionales que enfrenta la Municipalidad de San Ramón para la promoción de programas recreativos dirigidos a poblaciones jóvenes. Universidad de Costa Rica. (Trabajo sin publicar del curso Seminario de Realidad Nacional).

Alfaro, M.; Campos, R.; Gómez, K. y Ledezma, M. (2011). Prácticas y motivaciones 
de consumo de sustancias adictivas en colegiales de la RO. Universidad de Costa Rica. (Trabajo sin publicar del curso Seminario de Realidad Nacional).

Álvarez, L.; Bolaños, Y.; Castro, R.; Cortés, J.; Espinoza, A.; Ramírez, K. y Vega, V. (2010). Proyecto Casa Infantil de la UCRSO. Investigación evaluativa de sus objetivos. Universidad de Costa Rica. (Trabajo sin publicar del curso Seminario de Realidad Nacional).

Alvarez, J.; Artavia, R.; Carvajal, W.; Jiménez, S.; Morales, C. y Villalobos, M. (2011). Estrategias de afrontamiento del estrés que emplean los profesores de la UCR-SO. Universidad de Costa Rica. (Trabajo sin publicar del curso Seminario de Realidad Nacional).

Angulo, A.; Cruz, M.; Fernández, M. y Solano, S. (2009). Enseñanza interactiva de las matemáticas. Condiciones físicas, ambientales y espaciales requeridas en el aula. Universidad de Costa Rica. (Trabajo sin publicar del curso Seminario de Realidad Nacional).

Araya, M.; Méndez, N.; Ponce, E. y Varas, M. (2007) Prácticas Educativas para la promoción de la salud en los Centros Educativos de Primaria de la RCO. Universidad de Costa Rica. (Trabajo sin publicar del curso Seminario de Realidad Nacional).

Araya, A.; Elizondo, A.; Mora, G.; y Umaña, K. (2008). Valoración del desempeño que hacen los y las usuarias de los y las funcionarias del EBAIS de Tacares de Grecia. Universidad de Costa Rica. (Trabajo sin publicar del curso Seminario de Realidad Nacional).

Araya, F.; Arce, M.; Marín, R.; Ramírez, K. y Rojas, G. (2011). MUSADE. Valoración de los servicios que ofrece en la Región de Occidente a las usuarias. Universidad de Costa Rica. (Trabajo sin publicar del curso Seminario de Realidad Nacional).

Araya, M.; Arce, C.; Arguedas, M.; Chavarría, P. y Johnson, S. (2012). Ventajas y desventajas de la migración de combustible diesel al gas licuado de petróleo (GLP). Universidad de Costa Rica. (Trabajo sin publicar del curso Seminario de Realidad Nacional).

Araya, M.; Arias, D.; Chavarría, N.; Jiménez, C. y Urbina, D. (2012). Actitudes del-la docente hacia las estudiantes madre UCR-SO. Universidad de Costa Rica. (Trabajo sin publicar del curso Seminario de Realidad Nacional).

Arce, A.; Cascante, A.; Cordero, J.; Cubero, M. y Mora, M. (2007). Impacto del programa "Ejercicios v Recreación. Estilos de vida saludable al Adulto Mayor" en su calidad de vida. Universidad de Costa Rica. (Trabajo sin publicar del curso Seminario de Realidad Nacional).

Arce, C.; Jiménez, L. y Rodríguez, M. (2010). Uso de videojuegos y sentido de autoeficacia en estudiantes de colegio. Universidad de Costa Rica. (Trabajo sin publicar del curso Seminario de Realidad Nacional).

Arias, A.; Horna, F.; Piedra, R. y Rojas, A. (2007). Incentivos económicos de FONABE y motivación para continuar en el sistema educativo. Universidad de Costa Rica. (Trabajo sin publicar del curso Seminario de Realidad Nacional).

Arias, E.; Chacón, L.; Huertas, B. y Palma, D. (2011). Factores comunales y familiares asociados al consumo de drogas. Universidad de Costa Rica. (Trabajo sin publicar del curso Seminario de Realidad Nacional).

Arras, A. y Jáquez, J. (2008). Comunicación y cambio organizacional. Revista Latina de Comunicación Social. 63: 418-434.

Arroyo, D.; Funes, J.; Hérnandez, A. y Ramírez, W. (2009). Eficiencia percibida por los usuarios del servicio de Resolución Alternativa de Conflictos. San Ramón. Universidad de Costa Rica. (Trabajo sin publicar del curso Seminario de Realidad Nacional).

Artavia, R.; Bolaños, L.; Ocampo, K.; Rojas, E.; Segura, G. y Vargas, G. (2010). Virtudes Humanísticas. Desarrollo en personas menores en condición de abandono albergadas. Universidad de Costa Rica. (Trabajo sin publicar del curso Seminario de Realidad Nacional). 
Badilla, J.; Mora, H.; Rodríguez, G. y Salas, M. (2011). Cumplimiento de objetivos de los programas de prevención comunitaria. Universidad de Costa Rica. (Trabajo sin publicar del curso Seminario de Realidad Nacional).

Barquero, A.; Fernández, M. y Salas, J. (2010). Conocimiento de los servicios por los y las usuarios. Biblioteca de Palmares. Universidad de Costa Rica. (Trabajo sin publicar del curso Seminario de Realidad Nacional).

Barquero, D.; Bonilla, D.; Corea, A. Ledezma, H. y Madrigal, P. (2012). Valoración de los y las docentes sobre la eficacia del programa D.A.R.E en la prevención de consumo de drogas en una población adolescente. Universidad de Costa Rica. (Trabajo sin publicar del curso Seminario de Realidad Nacional).

Barrantes, L.; Castro, G. y Ulate, G. (2009). Conocimiento de derechos en madres primerisas. Hospital de San Ramón. Universidad de Costa Rica. (Trabajo sin publicar del curso Seminario de Realidad Nacional).

Barrientos, A.; Cubero, M.; Salazar, A. y Villalobos, W. (2008). Evaluación organizativa de la Comisión de Emergencias de Grecia. Universidad de Costa Rica. (Trabajo sin publicar del curso Seminario de Realidad Nacional).

Barrios, J.; Campos, F.; Castillo, B.; Lobo, A. y Sánchez, M. (2008). Promoción de la Salud en la Sede de Occidente. Evaluación del programa. Universidad de Costa Rica. (Trabajo sin publicar del curso Seminario de Realidad Nacional).

Benavides, M.; Chávez, D.; Fonseca, J.; Ramírez, A. y Rodríguez, P. (2011). Fortalezas universitarias para el apoyo a la Casita Infantil de la UCR, Sede de Occidente. Universidad de Costa Rica. (Trabajo sin publicar del curso Seminario de Realidad Nacional).

Bleger, J. (1985). Temas de psicología (Entrevista y grupos). Buenos Aires: Nueva Visión.

Bolaños, L.; Bolaños, Y.; González, M.; Mora, T. y Ledezma, A. (2009) Valoración de condiciones físicas y sociales y el sentido de autoeficacia en estudiantes de residencias UCR-SO. Universidad de Costa Rica. (Trabajo sin publicar del curso Seminario de Realidad Nacional).

Bolaños, Y.; Chavarría, S.; Cubero, J. e Hidalgo, R. (2009). Evaluación de los docentes formados sobre la eficacia del TCU: "Fortaleciendo la Educación Cooperativa" de la Sede de Occidente. Universidad de Costa Rica. (Trabajo sin publicar del curso Seminario de Realidad Nacional).

Brenes, A.; Carranza, E.; Castro, M.; Castro, C. y Salas, D. (2008). Evaluación del programa: "Pro Ayuda a la persona discapacitada". Conocimiento de la población meta sobre los servicios. Universidad de Costa Rica. (Trabajo sin publicar del curso Seminario de Realidad Nacional).

Cable, D. y Furst, S. (2008). Employee Resistance to Organizational Change: Managerial Influence Tactics and Leader-Member Exchange. Journal of Applied Psychology. 93 (2): 453-462.

Calvo, M.; Hernández, V.; Porras, G. y Umaña, G. (2008). Conocimiento del programa "Adolescente Madre". Evaluación de la campaña radial. Universidad de Costa Rica. (Trabajo sin publicar del curso Seminario de Realidad Nacional).

Calvo, A.; Chacón, M.; Hernández, D.; Murillo, E.; Novo, M.; Rodríguez, F. y Reyes, R. (2009). Implementación del Manual de Atención Integral en la Salud de los Niños (as\} en el Escenario Escolar en la Región de Occidente. Universidad de Costa Rica. (Trabajo sin publicar del curso Seminario de Realidad Nacional).

Campos, A.; Carranza, A.; Vargas, S. y Castillo, P. (2007). Opinión de los jóvenes del cantón central de San Ramón a cerca de las actividades deportivas - recreativas impulsadas por el gobierno local para la promoción de la salud. Universidad de Costa Rica. (Trabajo sin publicar del curso Seminario de Realidad Nacional).

Campos, D.; González, G.; Hernández, A. y Rodríguez, H. (2008). Los Biodigestores: Conocimientos sobre la tecnología en porcicultores de Grecia. Universidad de 
Costa Rica. (Trabajo sin publicar del curso Seminario de Realidad Nacional).

Campos, D.; Ramírez, C.; Román, L.; Salazar, L. y Vega, K. (2008). Satisfacción de los y las usuarias con los servicios que brinda la cooperativa CoopeTacares. Universidad de Costa Rica. (Trabajo sin publicar del curso Seminario de Realidad Nacional).

Campos, K. y Rodríguez, A. (2008). INA. Adecuación entre la oferta de carreras y la demanda laboral. Universidad de Costa Rica. (Trabajo sin publicar del curso Seminario de Realidad Nacional).

Carr, C.; Hernández, E.; Hidalgo, J.; Méndez, W. y Solano, V. (2010). Resistencia campesina. Características personales de productores de café que se mantienen en la actividad. Universidad de Costa Rica. (Trabajo sin publicar del curso Seminario de Realidad Nacional).

Carvajal, A. (2009). Desarrollo y postdesarrollo: Modelos y alternativas. Cali: Universidad del Valle.

Carvajal, S.; Castillo, M. y Cortés, A. (2011). Conocimiento sobre sexualidad que tienen los padres y madres de hijos-as entre 10 y 16 años. Universidad de Costa Rica. (Trabajo sin publicar del curso Seminario de Realidad Nacional).

Castro, J.; Suazo, D.; Vargas, C. y Vargas, C. (2012). Burnout en cuidadores-as de personas adultas mayores. Universidad de Costa Rica. (Trabajo sin publicar del curso Seminario de Realidad Nacional).

Chantarasombat, C. (2011) Developing Community Health Conditions for Happiness, Phase 1. Journal of Social Sciences, 7 (4): 627-631.

Charpentier, K.; Fernández, D.; Montoya, M.; Jiménez, D. y Quesada, D. (2007) Satisfacción de los estudiantes de I y II ciclo con respecto al servicio de comedor escolar. Universidad de Costa Rica. (Trabajo sin publicar del curso Seminario de Realidad Nacional).

Chavarria, C. (2009). Locus de control y selección temática televisiva en estudiantes que acuden a colegios catalogados como violentos de zonas urbanas y rurales. Tesis para optar al grado de doctorado. San José: Universidad Para La Paz.

Chavarría, C. y Robert, J. (2011). Situación de niños, niñas y adolescentes que viajan no acompañados por la Región Centroamericana. San José: Organización Internacional de las Migraciones.

Chavarría, C. (2012). Estructura Social y Locus de Control en colegios catalogados como violentos de zonas urbanas y rurales. Evidencias de su relación como insumo para la promoción de una Cultura de Paz. Revista Reflexiones. San José: UCR. (En prensa)

Chavarría, F. y Vargas, E. (2011). Diseño urbanístico y sentido de inseguridad en personas que realizan actividades habituales en el cantón de San Ramón. Universidad de Costa Rica. (Trabajo sin publicar del curso Seminario de Realidad Nacional).

Chaves, D.; Cisneros, G.; Murillo, C. y Zamora, R. (2007). Organizaciones que utilizan procesos de producción con tecnologías limpias. Conocimiento de los habitantes de la RCO. Universidad de Costa Rica. (Trabajo sin publicar del curso Seminario de Realidad Nacional).

Chávez, A.; Lizano, M.; Morera, J. y Rojas, G. (2008). Evaluación del Proyecto de erradicación de precarios en Bajo Tejares de la Municipalidad San Ramón. Universidad de Costa Rica. (Trabajo sin publicar del curso Seminario de Realidad Nacional).

Chomsky, N. (2004). Democracia y mercados en el nuevo orden mundial. En: Globalización y cultura: una aproximación a los problemas del mundo a inicios del tercer milenio. San José: Alma Mater. 283-315.

Cordero, J.; Fonseca, C.; Lobo, B.; Quesada, M. y Quesada, M. (2008). Dinámicas de trabajo interno para fomentar el desarrollo integral de las personas adultas mayores. Universidad de Costa Rica. (Trabajo sin publicar del curso Seminario de Realidad Nacional).

Corea, O.; Esquivel, K.; Fuentes, Y. y Rodríguez, A. (2008). Efectos psicosociales del concurso: Semilla de Arco Iris: MUSADE. Universidad de Costa Rica. (Trabajo sin 
publicar del curso Seminario de Realidad Nacional).

Corrales, K.; Jiménez, S.; Muñoz, A. y Soto, V. (2007) Accesibilidad de personas discapacitadas a las instalaciones físicas de las escuelas públicas y privadas del distrito central de San Ramón. Universidad de Costa Rica. (Trabajo sin publicar del curso Seminario de Realidad Nacional).

Corrales, D.; Madrigal, J.; Rodríguez, J.; Sanabria, L. y Soto, M. (2007). Procedimientos y criterios utilizados en construcciones de áreas recreativas y urbanizaciones en la RCO para el cumplimiento de la ley 7600. Universidad de Costa Rica. (Trabajo sin publicar del curso Seminario de Realidad Nacional).

Crouch, C. (2004). Posdemocracia. México: Taurus.

Davis, K. y Newstrom, J. (2000) Comportamiento organizacional. México: Mc. Graw Hill.

Delgado, D.; González, A.; Lazo, J.; López, G.; Sequeira, K. y Vargas, S. (2006). Evaluación de los objetivos de los programas de apoyo a víctimas de violencia intrafamiliar brindados en MUSADE. Universidad de Costa Rica. (Trabajo sin publicar del curso Seminario de Realidad Nacional).

Delgado, L.; Quesada, A. y Salazar, S. (2012). Valoración del desempeño que hacen los y las usuarias de los y las funcionarias del EBAIS de Piedades Sur en San Ramón.. Universidad de Costa Rica. (Trabajo sin publicar del curso Seminario de Realidad Nacional).

Díaz, G.; Jiménez, V.; Pérez, R. Prendas, S. y Santamaría, D. (2007). Necesidades psicosociales en la población infantil (0-5 años) de las madres que integran la Cooperativa Bajo Tejares. Universidad de Costa Rica. (Trabajo sin publicar del curso Seminario de Realidad Nacional).

Elizondo, E.; Granados, A.; Morales, G.; Quesada, D. y Villalobos, L. (2010). Autodescripción, estrategia de resolución de problemas y cuido del medio ambiente en niños-as de preparatoria. Universidad de Costa Rica. (Trabajo sin publicar del curso Seminario de Realidad Nacional).
Estefanía, J. (2004) ¿Qué es la globalización?. En: Globalización y cultura: una aproximación a los problemas del mundo a inicios del tercer milenio. San José: Alma Mater. 47-53.

Freud, S. (1930/1981). El malestar en la cultura. En: Sigmund Freud. Obras completas. Madrid: Biblioteca Nueva. Tomo III.

Fisas, V. (1998). Cultura de paz y gestion de conflictos. Barcelona: Ediciones UNESCO, Romanyá/Valls S.A.

Fromm, E. (1977). Anatomía de la Destructividad Humana. México: Siglo XXI.

Geibler, K. y Hege, M. (1997). Acción Socioeducativa. Modelos / Métodos / Técnicas. Madrid: Nancea S. A.

Gómez, J.; Gómez, G.; Rodríguez, B.; Sánchez, S. y Vega, J. (2012). Formas de trabajo individual y grupal para la atención de poblaciones con diferentes discapacidades psico-físicas. Universidad de Costa Rica. (Trabajo sin publicar del curso Seminario de Realidad Nacional).

González, M.; Sancho, L.; Ruíz, T. y Valle, D. (2008). Dificultades en la implementación lenguaje inclusivo en la documentación de la Municipalidad de San Ramón. Universidad de Costa Rica. (Trabajo sin publicar del curso Seminario de Realidad Nacional).

González, J.; Porras, L.; Rojas, F. y Salazar, M. (2009). Relación entre condiciones físico ambientales y valoración del desempeño en Guardias Civiles de San Ramón. Universidad de Costa Rica. (Trabajo sin publicar del curso Seminario de Realidad Nacional).

Guijarro, G. (1975). La concepción de hombre en Marx. Salamanca: Ed. Sígueme.

Hidalgo, F.; Rodríguez, E.; Torres, E. y Vargas, N. (2010). Motivación intrínseca - extrínseca y condiciones físico ambientales en un colegio público. Universidad de Costa Rica. (Trabajo sin publicar del curso Seminario de Realidad Nacional).

Méndez, D.; Núñez, N.; Torres, M. y Villegas, V. (2008). Necesidades femeninas en provectos urbanísticos. San Ramón. Universidad 
de Costa Rica. (Trabajo sin publicar del curso Seminario de Realidad Nacional).

Muñoz, J. (2008). Las rutas de aprendizaje: una estrategia novedosa de desarrollo rural con identidad territorial. El caso Cauca-Nariño (Colombia). Cuadernos Desarrollo Rural, 5 (60): 113-132.

León, F. (2009). El compromiso limitado. Un estudio sobre las razones estratégicas e identitarias de las acciones de resistencia y compromiso en el trabajo. Cuadernos de Relaciones Laborales. 27 (2): 115-143

Pereira, P. (2002). Necesidades humanas. Para una crítica a los patrones mínimos de sobrevivencia. Brasil: Cortez Editora.

Predişcan, M. y Săcui, V. (2011) Opportunity to reduce resistance to change in a process of organizational chance. Annals of the University of Oradea, Economic Science Series. 698 - 702 .

Quesada, L. (2000). Desarrollo institucional. Perspectiva de género en el desarrollo local. En: Cuadernos de Ciencias Sociales. Participación para el desarrollo local II. San José: FALCSO. 43-54.

Ramírez, N. y Rodríguez, S. (2010). Formación humanística. Valoración de los y las estudiantes de la UCR, Sede de Occidente. Universidad de Costa Rica. (Trabajo sin publicar del curso Seminario de Realidad Nacional).

Robbins, S. (1987). Comportamiento organizacional. Conceptos, controversias y aplicaciones. México: Prentice Hall.

Rodríguez, E.; Salazar, B.; Varela, M. y Zamora, J. (2009). Potencialidades para la comercialización de productos orgánicos según comerciantes de Zarcero, Naranjo, San
Ramón y Grecia. Universidad de Costa Rica. (Trabajo sin publicar del curso Seminario de Realidad Nacional).

Rodríguez, B.; Sánchez, R. y Soto, K. (2011). Actitudes hacia la homosexualidad en estudiantes de la UCR, Sede de Occidente. Universidad de Costa Rica. (Trabajo sin publicar del curso Seminario de Realidad Nacional).

Santos, G. (2004) La globalidad neoliberal. En: Globalización y cultura: una aproximación a los problemas del mundo a inicios del tercer milenio. San José: Alma Mater. 76-89.

Schwars, S. y Ros, M. (1995). Values in the West: A theoretical and empirical challenge to the individualism - collectivism cultural dimension. World Psychology, 1: 91-122.

Taghvaei, M. y Shaykh-Baygloo, R. (2011) A Survey of Sub-provincial Disparities of HDI in Iran. Australian Journal of Basic and Applied Sciences, 5(8): 720-728.

Tamayo, Á. y De Oliveira, L. (2001) Valores del trabajo y valores de las Organizaciones. En: Ros, M.; Gouveia, V. Psicología social de los valores humanos. Desarrollos teóricos, metodológicos y aplicados. Madrid: Biblioteca Nueva. 325 - 352.

Universidad de Costa Rica (2009). Acción Social. [en línea] http://accionsocial.ucr.ac.cr/web/ tcu/seminario-de-realidad-nacional. Consultada el 17 de setiembre del 2012.

Valverde, j. (2000) Globalización y desarrollo local. En: Cuadernos de Ciencias Sociales. Participación para el desarrollo local I. San José: FLACSO. 30-51. 